\title{
An Empirical Investigation of the Option Value of College Enrollment
}

\author{
By KeVIn M. STANGE*
}

\begin{abstract}
This paper quantifies the option value arising from sequential schooling decisions made in the presence of uncertainty and learning about academic ability. College attendance has option value since enrolled students have the option, but not obligation, to continue in school after learning their aptitude and tastes. I estimate that option value accounts for $14 \%$ of the total value of the opportunity to attend college for the average high school graduate and is greatest for moderate-aptitude students. Students' ability to make decisions sequentially in response to new information increases welfare and also makes educational outcomes less polarized by background.
\end{abstract}

JEL: I21, J24, D83

Since the pioneering work of Gary S. Becker and Jacob Mincer, the application of investment theory to the study of individuals' education decisions has become commonplace. People are assumed to weigh short-term costs against future benefits and choose the schooling level that maximizes welfare. This static framework abstracts from uncertainty and suggests that few people should drop out if the marginal earnings gain from graduating is high, as it appears to be. In reality, schooling decisions involve much uncertainty, outcomes often deviate from expectations, and dropout is common. ${ }^{1}$ Despite its salience and its importance to investment generally, uncertainty has historically received relatively little attention in the study of education. ${ }^{2}$

This paper examines the consequences of educational uncertainty using a structural model in which schooling decisions are sequential and academic ability is learned through grades. Since psychic schooling costs depend on ability, people refine their expectations of them over time. This set-up is analogous to Pindyck's (1993) model of "technical" cost uncertainty, where the cost of completing a long-term project is revealed only as in-

* Stange: Ford School of Public Policy, University of Michigan, 735 S. State Street \#5236, Ann Arbor, MI, 481093091, kstange@umich.edu. I am particularly thankful to David Card for many helpful discussions and invaluable advice throughout the duration of this project and to David S. Lee, Enrico Moretti, Steve Raphael, and Emmanuel Saez for their guidance. This work also benefited from discussions with Peter Arcidiacono, Raymundo Campos, Ada Chen, Raj Chetty, Avraham Ebenstein, Dan Hartley, Jane Herr, Robert Johnson, Damon Jones, Ashley Langer, Ron Lee, Nate Miller, Paulina Oliva Vallejo, Marit Rehavi, Megan Tompkins-Stange, and numerous seminar participants. Financial support for this work was provided by the National Institute for Child Health and Human Development (Interdisciplinary Training Grant No. T32-HD007275), the U.C. Berkeley Institute for Business and Economics Research, and the Center for Labor Economics at U.C. Berkeley. All errors are of course my own.

${ }^{1}$ For instance, only $51 \%$ of 1982 high school seniors who intended to earn a Bachelor's degree had done so by 1992 , while $16 \%$ of those planning to earn less than a four-year degree eventually did according to the National Center for Educational Statistics, 2004 Digest of Educational Statistics Table 307.

${ }^{2}$ Uncertainty is at the heart of a burgeoning body of very recent empirical work on schooling, as surveyed by James J. Heckman, Lance J. Lochner, and Petra E.Todd (2006). In the investment literature, most relevant here is the work related to real options collected in Avinash K. Dixit and Robert S. Pindyck (1994). 
vestment proceeds. Option value arises in this context since students have the option, but not obligation, to continue in school after learning their aptitude and tastes. My estimates suggest option value is substantial for the average high school graduate and is greatest for moderate-ability students. Their decisions are particularly sensitive to new information, so they derive the most value from learning it. The ability to condition sequential education decisions on new information increases welfare and also makes educational outcomes less polarized by background. Option value also rationalizes dropout in the presence of the substantial degree or "sheepskin" effects.

One implication is that policies that restrict dynamic flexibility curtail welfare most for those closest to the decision margin. School tracking, for example, will have the greatest impact on the welfare of students who are most uncertain about their fit with vocational or academic tracks. The general setup can be used to examine a wide range of phenomenon - job choices, marital decisions, health investments - in which decisions are sequential, partially irreversible, and responsive to new information.

This paper quantifies the importance of uncertainty and computes option value through simulations of a structural dynamic model, which is estimated using postsecondary transcript data on a recent cohort of U.S. men from the National Educational Longitudinal Study (NELS). The model encompasses enrollment decisions and grade outcomes over four years as well as the decision to start at a two-year (community) or four-year college. I simulate educational outcomes and welfare using the dynamic model and compare this to the counterfactual scenario wherein individuals commit to an educational outcome before enrolling in college. The welfare difference between these two scenarios is the value of the option to respond to the information received during college. ${ }^{3}$

I assume that enrollment reveals three pieces of information. The first is collegiate aptitude, which influences the persistent psychic costs (or benefits) from school attendance. Enrollment provides information in the form of course grades which are used to predict the future desirability of school. Non-persistent shocks to the relative cost (or benefit) of schooling are the second. These shocks combine many factors - getting ill, having a parent lose a job, having a winning football team - that are not expected to persist over time. The final source of uncertainty is about labor market opportunities associated with higher levels of education. Expected lifetime income increases with education but the specific realization is unknown ex-ante. Individuals learn of these opportunities only if they actually enroll. ${ }^{4}$ Since decisions can be conditioned on all this information, acquiring it has value.

Estimates suggest that uncertainty about college completion is empirically important; unanticipated taste shocks are half as large as the returns to the final year of college and dwarf direct tuition fees at public colleges. There is also evidence of learning about ability - over time people put increased weight on course grades in their continuation

\footnotetext{
${ }^{3}$ In order to isolate the value of new information, I adopt Dixit and Pindyck's (1994) definition of option value, which nets out the continuation value that arises even with no uncertainty if returns are nonlinear. Heckman, Lochner, and Todd (2006), Heckman and Salvador Navarro (2007), and Heckman and Sergio Urzua (2008) define option value inclusive of this continuation value. See Section IIC.

${ }^{4}$ Such preference and labor market shocks are common features in the dynamic structural models of Michael P. Keane and Kenneth I. Wolpin (1997) and others.
} 
decisions. Because of this uncertainty, the average high school graduate would be willing to pay $\$ 14,900$ (in 1992 dollars) to maintain the ability to decide sequentially, with moderate-ability students (for whom educational outcomes are most uncertain) willing to pay even more (up to $\$ 25,000$ in 1992 dollars). Option value accounts for $14 \%$ of the total value of the opportunity to attend college among all high school graduates and $32 \%$ for those closer to the enrollment margin. Approximately $60 \%$ of this value comes from the information received in the first year of college. The ability to make decisions sequentially increases both enrollment and dropout, but also closes a quarter of the welfare gap between the first-best scenario (individuals maximize welfare ex-post) and the static one (individuals commit to outcomes ex-ante).

Though most previous treatment of this subject has been theoretical, recent empirical work also underscores the importance of schooling uncertainty and option value. ${ }^{5}$ For instance, Joseph G. Altonji (1993) finds large differences between mean ex-ante and ex-post returns to starting college and Flavio Cunha, Heckman, and Navarro (2005) conclude that $30 \%$ of people would change their schooling decisions if they had perfect information. Stacey H. Chen (2009) estimates that $80 \%$ of potential wage variation reflects uncertainty and this share varies across education levels. Uncertainty is clearly important empirically.

This paper is in the tradition of the multi-period dynamic structural schooling models exemplified by Keane and Wolpin (1997), but with two key contributions. First, I augment their basic model to include learning about ability through course grades, similar to Peter Arcidiacono (2004). Psychic costs (which depend on ability) are very important to schooling decisions, but their nature is not well understood. ${ }^{6}$ Heckman and Navarro (2007) discuss identification of a general model which permits learning about seriallypersistent attributes (such as psychic costs), but leave estimation for future work. Learning about academic ability is one source of option value not present in previous empirical work. ${ }^{7}$

Second, I examine the properties and consequences of option value using a fully estimated dynamic structural model. Heckman, Lochner, and Todd (2006) caution that rates of return to schooling depend on the empirical importance of option value, yet previous work ignores this. They provide preliminary estimates of it using a calibrated model with exogenous dropout, concluding that much more work is needed on the subject. ${ }^{8}$ This paper uses a simple theoretical model to show how uncertainty creates option value and influences enrollment decisions, particularly for those at the margin. These properties

\footnotetext{
${ }^{5}$ Burton A. Weisbrod (1962) was the first to point out that education has option value. Also see the theoretical work of Yochanan Comay, Arie Melnik, and Moshe A. Pollatschek (1973); Uri Dothan and Joseph Williams (1981); and Charles F. Manski (1989).

${ }^{6}$ See Heckman, Lochner, and Todd (2006) for a discussion of recent evidence on the importance of psychic costs.

${ }^{7}$ Arcidiacono (2004) estimates the returns to various majors after controlling for dynamic selection, using course grades as a signal of subject-specific unobserved ability. His model and estimates could be used to quantify the option value arising from learning about subject-specific ability, as is also examined in Altonji (1993). Since he only examines students admitted to four-year colleges, however, his estimates cannot be used to investigate the importance of learning to enrollment decisions more generally.

${ }^{8}$ Work in progress by Heckman and Urzua (2008) is also quantifying option value using an estimated dynamic model of schooling.
} 
are quantified using the estimated structural model, in order to examine the empirical importance of option value to educational attainment, welfare, and policy. ${ }^{9}$

The rest of the paper proceeds as follows. Section I uses a simple two-period model to analyze how option value arises in the presence of educational uncertainty. This section states the definition of option value used in this study and discusses several of its properties. Section II presents the full empirical model and discusses issues related to its estimation. Estimation results are presented in Section III, which also includes a discussion of model fit. Section IV uses the estimated model to calculate the option value created by the sequential nature of schooling decisions. Section V concludes by identifying directions for future work as well as other applications.

\section{Modeling Educational Investment}

\section{A. The college dropout puzzle}

The static model of educational investment widely used in the literature is inconsistent with high levels of college dropout if degree wage effects are large. Consider a simple version of the traditional model first developed by Becker (1964) as discussed in David Card (1999). Individuals are assumed to maximize lifetime utility, which is a function of lifetime earnings and the (monetary and psychic) cost of schooling, $U=\ln y(S)-c(S)$, where $c(S)$ is some increasing and convex function of years of schooling. If $y(S)$ and $c(S)$ are continuous and differentiable, then the optimal schooling level $\left(S_{i}^{*}\right)$ satisfies the first order condition $\frac{d y_{i}\left(S_{i}^{*}\right)}{d S} \frac{1}{y_{i}\left(S_{i}^{*}\right)}=\frac{d c_{i}\left(S_{i}^{*}\right)}{d S}$. The benefit of an additional year of schooling (higher earnings) just offsets the additional costs (delayed earnings and psychic costs) at the optimum.

However, the returns to college appear to be highly non-linear with substantial degree or "sheepskin effects." ${ }^{10}$ Figure 1 presents estimates of the earnings production function for male high school graduates from the National Longitudinal Survey of Youth 1979 (NLSY79). The present discounted value of lifetime earnings minus tuition jumps discretely at four years of college, but is unrelated to schooling attainment until then. If psychic schooling costs are smooth, individuals should bunch at this discontinuity and very few people should fall in the intermediate ranges. Figure 1 also plots the distribution of postsecondary schooling attainment for men aged 35, who have presumably all completed their schooling. Consistent with the traditional model, zero (39\% of the sample) and four years (17\%) of college are the most frequent schooling outcomes. Ten percent attend college for two years, which partially reflects Associate's degree attainment. Contrary to the theory, however, there are many people whose schooling level puts them on the flat part of the earnings production function. Fully $28 \%$ of high school graduates

\footnotetext{
${ }^{9}$ Reduced form techniques are inadequate for quantifying option value, but they can be used to explore its importance to various decisions. For instance, Eric Eide and Geetha Waehrer (1998) examine whether students consider the likelihood of graduate school (and accompanying wage gains) when choosing a college major choice.

${ }^{10}$ There is a substantial literature that documents the existance of nonlinearities (or "sheepskin" effects) in the returns to education. See Thomas Hungerford and Gary Solon (1987); David A. Jaeger and Marianne E. Page (1996); Jin Heum Park (1999); and Heckman, Lochner, and Todd (2006).
} 


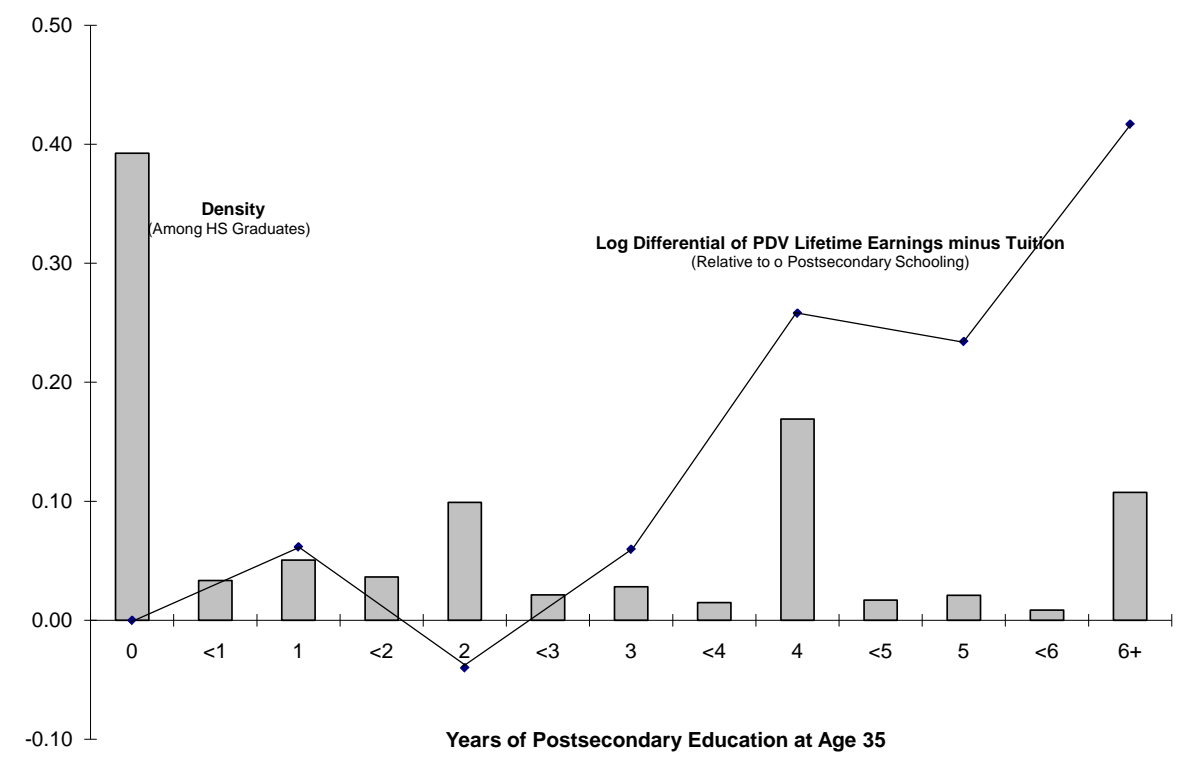

Figure 1. Returns to And Distribution of Postsecondary Education, Men

Note: Density is from IPUMS-CPS years 1985 to 1990 restricted to 35 year old male high school graduates. The solid line plots the coefficients from a linear regression of log lifetime earnings (minus average tuition) on a set of schooling level dummies and control variables using data from the NLSY. PDV of lifetime earnings are computed from age 18 to 62 assuming real income is constant from age 38 to 62 and a discount rate of 5 percent. Linear controls include dummies for ethnicity, four regions, urban, parents' education, high school GPA, AFQT, and the pairwise interactions between these last three variables. These OLS estimates only partially address the endogeneity and selection problems which complicate earnings comparisons by schooling level.

drop out before finishing their fourth year of college. From the perspective of traditional human capital theory where individuals optimally choose their schooling level to equate the known marginal costs and benefits of an additional year, these individuals seemingly present an unexplained puzzle.

However, dropout can be rationalized when schooling decisions are sequential and the feasibility and desirability of degree completion is unknown ex-ante. As pointed out by Altonji (1993), uncertainty about the difficulty of graduating can interact with nonlinearities in the ex-post returns to schooling to create option value. Students with schooling outcomes on the flat part of the earnings curve may therefore be people for whom option value made enrollment worthwhile, even though the return was negative ex-post.

\section{B. A simple dynamic model of college enrollment and completion}

Now consider a simple dynamic model with two periods, which correspond to the first and second half of college. ${ }^{11}$ Utility is in dollars, individuals are assumed to be

\footnotetext{
${ }^{11}$ A similar two-period setup was used by Manski (1989); Altonji (1993); Christopher R. Taber (2000); and Arcidiacono (2004).
} 


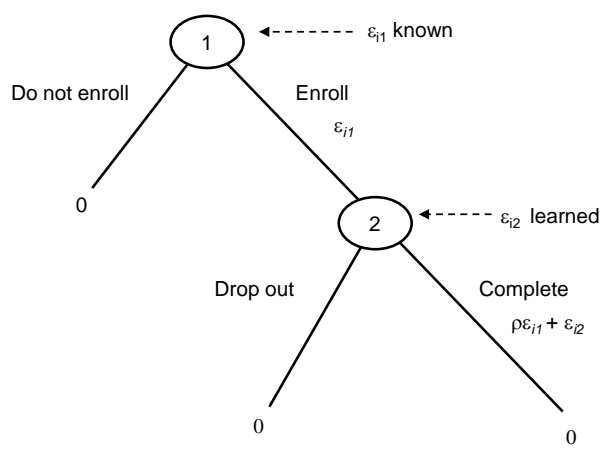

Figure 2. Simple Dynamic Model of College Enrollment and Completion

risk-neutral, and time discounting is ignored. At period one, individuals decide whether or not to enroll in college. Entering the labor market immediately provides zero utility but enrollment provides an individual-specific net return to the first half of college $\left(\varepsilon_{i, 1}\right)$ which is known throughout. At period two, those who enrolled decide whether or not to graduate. Dropping out provides no further utility but graduating provides additional utility of $\rho \varepsilon_{i, 1}+\varepsilon_{i, 2}$, where $\varepsilon_{i, 2}$ is revealed at the start of period two and $\operatorname{Cov}\left[\varepsilon_{i, 1}, \varepsilon_{i, 2}\right]=$ 0 . Individual-specific returns to the second half of college have a component that is known when the initial enrollment decision is being made $\left(\rho \varepsilon_{i, 1}\right)$ and one that is only learned after enrollment $\left(\varepsilon_{i, 2}\right)$. This specification allows the returns in each period to be correlated, so first period returns provide information about the desirability of attending the second period. For expositional simplicity, I normalize mean returns to zero in each period, $E\left[\varepsilon_{i, 1}\right]=E\left[\varepsilon_{i, 2}\right]=0 .{ }^{12}$ I focus on the case where returns are non-negatively correlated, $\rho \geq 0$. Figure 2 illustrates the structure and payoffs of the model.

Static model. First consider the fully static case where individuals make a single schooling decision between the three schooling outcomes (no enrollment, dropout, complete) at period one. Since they have no knowledge of $\varepsilon_{i, 2}$, they set it to its expected value when evaluating the payoffs. The decision rules of individual $i$ are thus:

$$
\begin{gathered}
\text { Enroll if }: \varepsilon_{i, 1}+\max \left\{0, \rho \varepsilon_{i, 1}\right\}>0 \\
\text { Complete if }: \rho \varepsilon_{i, 1}>0
\end{gathered}
$$

Individuals will enroll and complete if $\varepsilon_{i, 1}>0$ and not enroll otherwise. Here the static model predicts no dropouts; anyone for whom enrollment is desirable will also want to complete college. To see this, note that payoffs are $0, \varepsilon_{i, 1}$, and $\varepsilon_{i, 1}(1+\rho)$ for non-enrollees, dropouts, and completers, respectively, so completing college dominates

\footnotetext{
${ }^{12}$ The model can easily incorporate nonlinearities in returns by setting $E\left[\varepsilon_{i, 2}\right]=r>E\left[\varepsilon_{i, 1}\right]$. Nonlinearities are not necessary to create option value, but simply highlight option value's importance in explaining dropout. The model I actually estimate uses the empirical returns to each year of college, which permit nonlinearities.
} 
dropping out if $\rho>0$. The presence of non-linear returns (e.g. $E\left[\varepsilon_{i, 2}\right]=r>E\left[\varepsilon_{i, 1}\right]$ ) will only magnify this result. With negatively correlated returns $(\rho<0)$, the static model predicts that some people will drop out but all who do will have positive ex-post payoffs. ${ }^{13}$

Dynamic model. Now consider the dynamic case, where individuals only have to make the enrollment decision at period 1. People will enroll if the expected utility from doing so is greater than zero, where expectations are taken over the distribution of the unknown second-period returns $\varepsilon_{i, 2}$. The model is solved starting with the completion decision in period two, when all parameters are known. The decision rules of individual $i$ are thus:

$$
\begin{aligned}
& \text { Enroll if }: \varepsilon_{i, 1}+E\left[\max \left\{0, \rho \varepsilon_{i, 1}+\varepsilon_{i, 2}\right\}\right]>0 \\
& \text { Complete if : } \rho \varepsilon_{i, 1}+\varepsilon_{i, 2}>0
\end{aligned}
$$

The enrollment decision incorporates not only the immediate payoffs $\left(\varepsilon_{i, 1}\right)$ but also the expectation of future ones $\left(E\left[\max \left\{0, \rho \varepsilon_{i, 1}+\varepsilon_{i, 2}\right\}\right]\right)$. Now the enrollment and completion decisions are not completely coupled since completion can be conditioned on the realized value of $\varepsilon_{i, 2}$. This property has several implications for the level of enrollment, dropout, and welfare, to which I now turn.

\section{The option value of college enrollment}

A key feature of the dynamic model where dropout is endogenous is that the expected net utility gain from completing college is truncated at zero. If $\varepsilon_{i, 2}$ is sufficiently adverse, then individuals will choose to drop out rather than assume this adverse shock. By providing information about the desirability of completion, enrollment thus has value beyond the utility provided in the first period directly. This section defines the option value created by uncertainty and discusses the implications of option value for educational outcomes and welfare.

Enrollment is valuable because it leads to outcomes people may want to commit to ex-ante and because it provides information about the desirability of completion. The value of the opportunity to enroll can be decomposed into these two parts.

$$
V_{\text {dynamic }}\left(\varepsilon_{i, 1}\right)=V_{\text {static }}\left(\varepsilon_{i, 1}\right)+\text { OptionValue }\left(\varepsilon_{i, 1}\right)
$$

$V_{\text {dynamic }}\left(\varepsilon_{i, 1}\right)$ is the value of the opportunity to enroll for individual $i$ (as a function of $\left.\varepsilon_{i, 1}\right)$ in the dynamic setting where individuals can drop out if continuation ends up being undesirable. $V_{\text {static }}\left(\varepsilon_{i, 1}\right)$ is the value of the enrollment opportunity in the static case, where individuals commit to an educational outcome ex-ante. Define $\bar{\varepsilon}_{d, 1}$ as the critical value above which enrollment is optimal in the dynamic setting and $\bar{\varepsilon}_{s, 1}$ analogously in

\footnotetext{
${ }^{13}$ This is a key difference between the static and dynamic models. While people who drop-out in the static model will have positive ex-post payoffs, some drop-outs in the dynamic context will have negative ex-post payoffs.
} 
the static setting. ${ }^{14}$

From above we have $V_{\text {dynamic }}\left(\varepsilon_{i, 1}\right)=\max \left(0, \varepsilon_{i, 1}+E\left[\max \left\{0, \rho \varepsilon_{i, 1}+\varepsilon_{i, 2}\right\}\right]\right)$ and $V_{\text {static }}\left(\varepsilon_{i, 1}\right)=$ $\max \left(0, \varepsilon_{i, 1}+\max \left\{0, E\left[\rho \varepsilon_{i, 1}+\varepsilon_{i, 2}\right]\right\}\right)$. Thus option value can be written as:

$$
\begin{aligned}
\operatorname{OptionValue}\left(\varepsilon_{i, 1}\right)= & \underbrace{\max \left(0, \varepsilon_{i, 1}+E\left[\max \left\{0, \rho \varepsilon_{i, 1}+\varepsilon_{i, 2}\right\}\right]\right)}_{V_{\text {dynamic }}\left(\varepsilon_{i, 1}\right)} \\
& -\underbrace{\max \left(0, \varepsilon_{i, 1}+\max \left\{0, E\left[\rho \varepsilon_{i, 1}+\varepsilon_{i, 2}\right]\right\}\right)}_{V_{\text {static }}\left(\varepsilon_{i, 1}\right)}
\end{aligned}
$$

This definition of option value nets out the continuation value arising from nonlinear returns with no uncertainty, consistent with Dixit and Pindyck (1994). If completing the first year of college is required in order to enter the second year, then the first year has continuation value. Continuation value may cause people with negative first year returns to enroll if second year returns are sufficiently high. However, if second period returns are uncertain and future decisions can be conditioned on new information, then even individuals who expect negative returns in both periods $\left(\varepsilon_{i, 1}<0\right)$ may find it optimal to enroll. In this paper, I focus on this latter effect. Heckman, Lochner, and Todd (2006), Heckman and Navarro (2007), and Heckman and Urzua (2008) define option value inclusive of the continuation value, which is appropriate given their interest in estimating total returns. ${ }^{15}$ While my estimates of the opportunity to attend college includes both continuation and option value, this paper primarily focuses on the latter. Proposition 1 describes the properties of option value as defined in this paper.

PROPOSITION 1: (The properties of option value).

a) OptionValue $\left(\varepsilon_{i, 1}\right)$ is non-negative for all $\varepsilon_{i, 1}$.

b) OptionValue $\left(\varepsilon_{i, 1}\right)$ is greatest for individuals at the enrollment margin in the static model.

c) OptionValue $\left(\varepsilon_{i, 1}\right)$ is increasing and the critical value $\bar{\varepsilon}_{d, 1}$ is decreasing in the level of uncertainty (variance of $\varepsilon_{i, 2}$ ).

d) OptionValue $\left(\varepsilon_{i, 1}\right)$ reduces the dependence of educational outcomes on $\varepsilon_{i, 1}$.

e) The option to drop out improves welfare.

\section{PROOF:}

See Appendix.

Figure 3 illustrates these features of option value in this context through simulations. Panel A plots the value of the enrollment opportunity for a range of values of $\varepsilon_{i, 1}$ and

\footnotetext{
${ }^{14}$ Here $\bar{\varepsilon}_{s, 1}=0$ and $\bar{\varepsilon}_{d, 1}$ solves $V_{\text {dynamic }}\left(\varepsilon_{i, 1}\right)=0$.

${ }^{15}$ Roughly speaking, this distinction is a matter of how to treat the extent to which the option is "in the money" when it is granted. In the above notation, Heckman, Lochner, and Todd (2006) would define option value as :

$O V\left(\varepsilon_{i, 1}\right)=\max \left(0, \varepsilon_{i, 1}+E\left[\max \left\{0, \rho \varepsilon_{i, 1}+\varepsilon_{i, 2}\right\}\right]\right)-\max \left(0, \varepsilon_{i, 1}\right)$
} 
for different levels of uncertainty about $\varepsilon_{i, 2}$. The dotted line is the value of the enrollment opportunity in the static case, $V_{\text {static }}\left(\varepsilon_{i, 1}\right)$. This value is zero for those who choose not to enroll $\left(\varepsilon_{i, 1}<0\right)$ and then increases linearly with $\varepsilon_{i, 1}$. The dashed lines plot the value of the enrollment opportunity in the dynamic situation where $\varepsilon_{i, 2}$ is uncertain, $V_{\text {dynamic }}\left(\varepsilon_{i, 1}\right)$, for two different levels of uncertainty about $\varepsilon_{i, 2}$. The vertical distance between the dashed and dotted lines represents the Option Value $\left(\varepsilon_{i, 1}\right)$. For comparison, the solid line plots the average welfare in the full information counterfactual scenario where individuals can make education decisions to maximize welfare ex-post, after learning $\varepsilon_{i, 2}$. Figure 3 confirms that OptionValue $\left(\varepsilon_{i, 1}\right)$ is increasing in $\sigma$. In contrast to the standard view that uncertainty reduces welfare if agents are risk averse, here uncertainty combined with the ability to respond dynamically actually increases welfare by increasing the option value. As OptionValue $\left(\varepsilon_{i, 1}\right)$ increases due to increased uncertainty about $\varepsilon_{i, 2}$, enrollment becomes desirable to more people. This can also be seen in Figure 3: $\bar{\varepsilon}_{d, 1}$ is where the dashed lines intersect the horizontal axis. Even without nonlinearities, option value will make enrollment desirable to people for whom the first half of college is unproductive $\left(\varepsilon_{i, 1}<0\right)$. In Figure 3 , the vertical distance between the solid line and the others represents the welfare loss resulting from incomplete information about $\varepsilon_{i, 2}$. The ability to drop out after learning $\varepsilon_{i, 2}$ (the dashed line) closes much of this welfare gap.

The sources of the welfare gains coming from the ability to drop out can be seen more clearly by looking at educational outcomes under the various scenarios. The right panels of Figure 3 plot the fraction enrolling in (Panel B) and completing college (Panel C) under the static, dynamic, and full-information scenarios described above. Individuals in Group A receive no schooling in either the static or dynamic settings, though some (with high $\varepsilon_{i, 2}$ ) would enroll and graduate if they knew $\varepsilon_{i, 2}$ with certainty. Individuals in Group B are compelled to enroll despite their negative first period returns because of the informational value. Though many will eventually drop out, others will graduate and the costs of experimenting are not too high. This group receives considerably more education in the dynamic setting. Interestingly, a small subset of these individuals actually continue to graduation due to the sunk-cost nature of their period 1 investment, despite this being suboptimal ex-post. Group $\mathrm{C}$ benefits from the dynamic setting because they have the option to drop out if continuation is undesirable. In the static model, all commit to graduating, even if it is undesirable ex-post. Option value increases the welfare of this group by reducing their educational attainment.

\section{Implications for empirical work}

A simple dynamic model of college enrollment and completion was motivated by the failure of the static model to explain high rates of college dropout. In a dynamic setting, dropout occurs when new information reveals that continuation is not desirable. The opportunity to drop out in response to this information creates option value, which was shown to have important consequences for educational outcomes and welfare. Specifically, option value increases the incentive to enroll, particularly for those at the enrollment margin in the static model. Any model that ignores this value will necessarily 

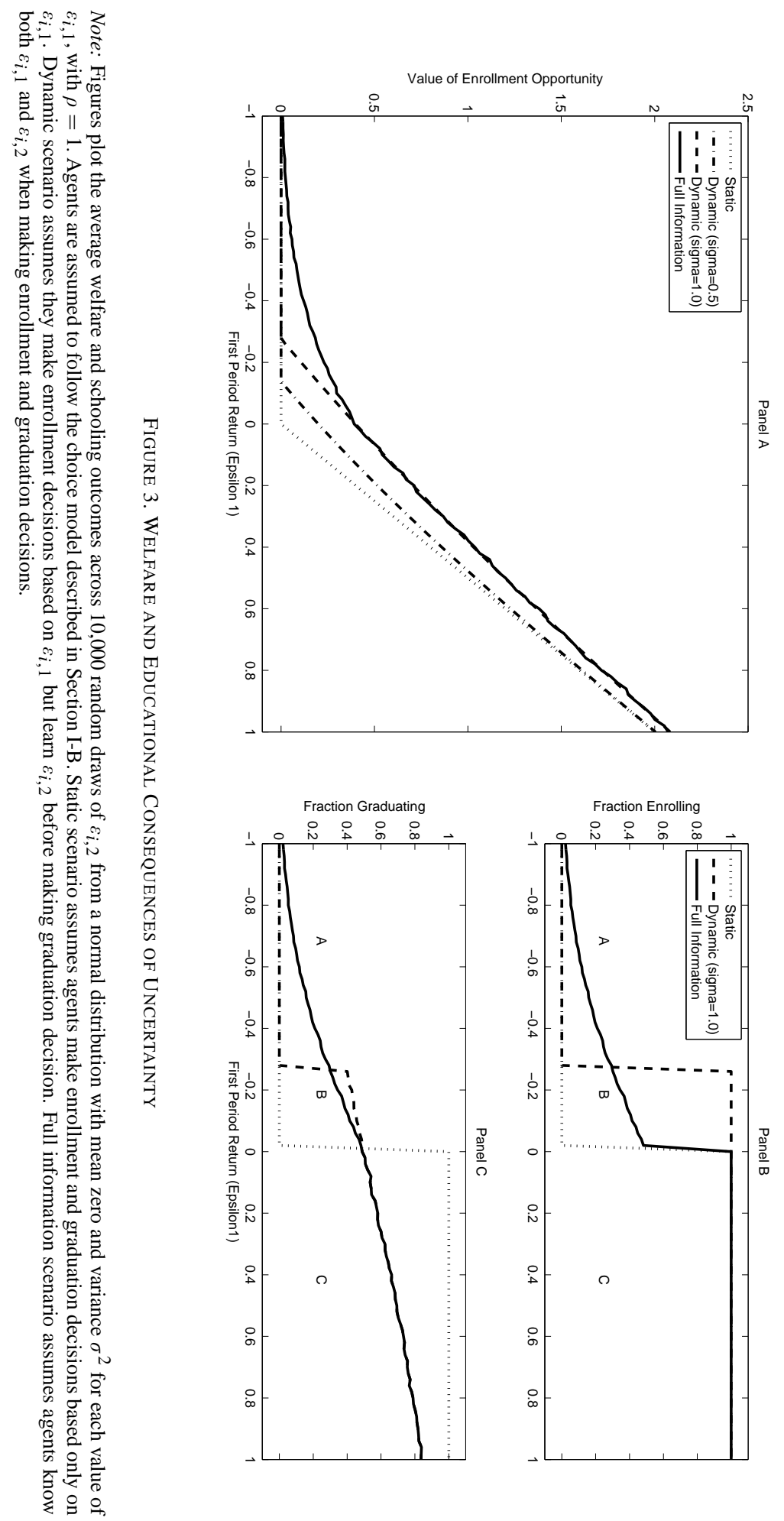
understate the incentive to enroll and mischaracterize the social desirability of college dropout.

\section{Empirical Implementation}

To characterize schooling uncertainty quantitatively, I estimate an empirical model that is a much richer version of the basic model presented above. The empirical model describes enrollment decisions and grade outcomes at four time periods and allows individuals to start at either a two-year or four-year college. The model includes several sources of uncertainty. Like many dynamic models, I include unanticipated shocks to the relative desirability of school and labor market entry at each point in time. For example, receiving an unusually favorable outside job offer or getting ill influences the relative desirability of schooling and work at a single period. These shocks are assumed to be serially uncorrelated. The second source of uncertainty is about academic aptitude, which influences taste for schooling throughout college. Students do not know for certain whether they are a "B" or "C" college student until they enroll. Grades following enrollment provide a signal of this unobserved ability and students learn about their aptitude through their grades. This section presents the key elements of the empirical model and discusses issues related to its estimation. A complete description of the full model is contained in the Web Appendix, which also includes a discussion of several important extensions.

\section{A. Data}

The model is estimated on a panel of 2055 men participating in the National Educational Longitudinal Study (NELS). NELS participants were first interviewed in 1988, while in 8th grade, then again in 1990, 1992, 1994, and 2000. Complete college transcripts were obtained in 2000 for most participants. The NELS transcript and survey data are used to construct the main variables used in the analysis: college enrollment indicators, grade outcomes, and baseline characteristics. I supplemented the NELS dataset with institutional characteristics obtained from the Integrated Postsecondary Education Data System (IPEDS) 1992 Institutional Characteristics survey. For each NELS individual, I merged on distance to the nearest two-year and four-year college (in miles) and average tuition levels at public two-year and four-year colleges in each state. ${ }^{16}$

I define a time period as one academic year and classify individuals by years of continuous college enrollment following high school graduation. Students are considered enrolled during year $t$ if they attempted at least six course units (approximately part-time status) at either a two-year or four-year school in both Fall and Spring of the academic year. Since income measures as adults do not appear in the NELS dataset, I estimate conditional expectations of lifetime income using data from an earlier cohort, male high

\footnotetext{
${ }^{16}$ Characteristics of the specific schools students attend (e.g. tuition) is not used in this analysis. Average tuition levels in each state are a more exogenous source of variation in the price of college than own-school tuition, which varies considerably between public and private institutions and is endogenous. Tuition levels are set at their 1992 levels thoughout, assuming students don't reoptimize in response to short-term tuition changes.
} 
school graduates from the National Longitudinal Survey of Youth 1979 (NLSY79). Using variables that are common in both the NLSY79 and the NELS (such as high school GPA, parental education, AFQT, ethnicity, urban and region), I estimate the parameters of a lifetime income equation using OLS and predict counterfactual lifetime income for individuals in the NELS sample. Essentially, I assume that individuals in my sample look at the experience of "similar" individuals twelve years older to form their income expectations. This approach is similar to the "reference group expectations" referred to by Manski (1991).

I restrict the dataset to on-time high school graduates with complete information on key baseline variables (high school GPA, AFQT, parents' education, family income, distance to nearest colleges) and complete college transcripts (unless no claim of college attendance). I also exclude residents of Alaska, Hawaii, and the District of Columbia. After these restrictions the final dataset contains 2055 men. Web Appendix A contains summary statistics and more details on how the dataset was constructed. Though these restrictions reduce the sample considerably, the final unweighted analysis sample is very similar to a nationally representative sample of the high school class of 1992 . Web Appendix B describes the counterfactual lifetime income estimation procedure.

\section{B. Model description}

I model schooling decisions in the four academic years after high school graduation. During the first period individuals decide whether to start at a four-year or two-year college, which I refer to as pathway choice, or to not enroll in college. The pathway chosen affects the level and timing of direct schooling costs (which may differ across individuals) and unmodeled college amenities. At each time period $t$ an individual chooses whether to enter the labor market (an absorbing state) and receive payoff $u_{i, t}^{w}$ or continue in school for another year. Continuing provides a payoff $u_{i, j, t}^{s}$ in period $t$ and the option to make an analogous work-school decision in period $t+1$, where $j=2,4$ denotes type of school (two-year or four-year). After period two, students that started at a two-year college must attend a four-year college if they want to continue in school. After period four, there are no more decisions to make and all individuals enter the labor market. Figure 4 depicts the structure of choices, information, and payoffs in the full empirical model, where the individual subscripts have been omitted.

Utility is in dollars. The indirect utility from discontinuing school and entering the labor market at period $t$ equals the expected present discounted value of lifetime income from period $t$ to age 62 (Income $e_{i, t}$ ) plus a random component $\varepsilon_{i, t}^{w}$. Note that $t$ subscripts a decision period so it is collinear with years of continuous education in this model. Lifetime income depends implicitly on years of continuous schooling, which is determined directly by when students leave school.

$$
u_{i, t}^{w}=\text { Income }_{i, t}+\varepsilon_{i, t}^{w}
$$

The expected indirect utility derived from attending school during year $t, u_{i, j, t}^{s}$, depends linearly on a type-specific intercept $\left(\alpha_{m, j}\right)$, expected unknown ability $\left(A_{i}\right)$, direct tuition 


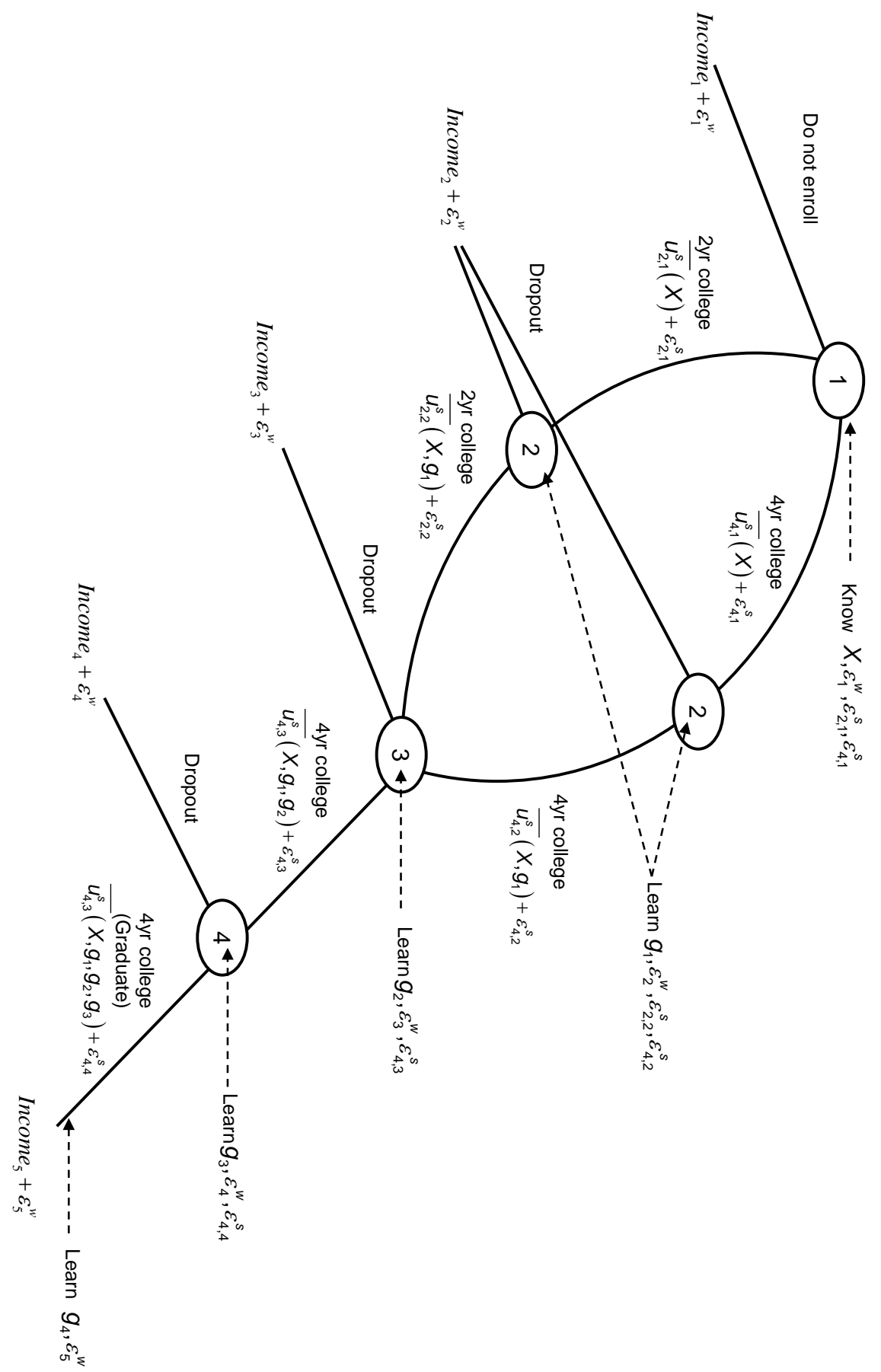


and commuting costs, and a random component $\varepsilon_{i, j, t}^{s}$. Distance $_{i, j, t}$ and Tuition $_{i, j, t}$ vary by the type of school, so individuals that start at a two-year school will pay community college tuition for the first two years then four-year college tuition for their third and fourth years. As a robustness check, I also estimate a model that includes a persistent utility cost associated with transferring from a 2-year to 4-year school. The random shocks $\left(\varepsilon_{i, j, t}^{s}, \varepsilon_{i, t}^{w}\right)$ are revealed to the individual prior to making the period $t$ decision.

$$
u_{i, j, t}^{s}=\alpha_{0, j}+\alpha_{m, j}+\alpha_{A} E_{t}\left[A_{i}\right]-\left(\alpha_{D} \text { Distance }_{i, j, t}+\text { Tuition }_{i, j, t}\right)+\varepsilon_{i, j, t}^{s}
$$

The term $\alpha_{A} E_{t}\left[A_{i}\right]$ captures the preference for school (in dollar terms) that covaries with its expected difficulty. ${ }^{17}$ Individuals do not know $A_{i}$ at any time, so they form expectations of it when making their period- $t$ decisions. ${ }^{18} \mathrm{I}$ assume that individuals form rational expectations of their performance in school. ${ }^{19}$ In period one, I make the parametric assumption that the conditional expectation of $A_{i}$ on baseline characteristics depends linearly on a type-specific intercept $\left(\gamma_{m}\right)$, high school grade point average $\left(H S g p a_{i}\right)$, percentile score on the AFQT, and whether a parent has a college degree $\left(\operatorname{Par} B A_{i}\right)$ :

$$
E_{1}\left[A_{i}\right]=E\left[A_{i} \mid X_{i}\right]=\gamma_{0}+\gamma_{m}+\gamma_{G} \operatorname{HSgpa}_{i}+\gamma_{T} A F Q T_{i}+\gamma_{P} \operatorname{ParBA}_{i}
$$

At the end of each year, students enrolled in college learn their performance during that year, which is measured by the college grade point average (on a four-point scale) during period $t$. I assume that grades provide a noisy signal of $A_{i}: g_{i, t}=A_{i}+\varepsilon_{i, t}^{g}$. Grade shocks are assumed to be serially uncorrelated and normally distributed: $\varepsilon_{i, t}^{g} \sim N\left(0, \sigma_{G t}\right)$. With learning, individuals update their belief about $A_{i}$ in response to new information received through grades. I make the parametric assumption that the conditional expectation of $A_{i}$ is a weighted average of the unconditional expectation and students' cumulative grade point average. The weights are parameters to be estimated and are allowed to vary by sector as a robustness check. ${ }^{20}$

$$
E_{t}\left[A_{i}\right]=\gamma_{X t} E\left[A_{i} \mid X_{i}\right]+\left(1-\gamma_{X t}\right) \sum_{q=1}^{q=t-1} \frac{g_{i, q}}{t-1} \text { if } t>1
$$

To permit a general structure of correlation between unobservable preferences and

\footnotetext{
${ }^{17}$ An alternative interpretation is that $\alpha_{A} E_{t}\left[A_{i}\right]$ instead captures expected individual-specific returns to each year of schooling. I discuss this possibility in the next section.

${ }^{18}$ This specification can be motivated by a model where the difficulty of year $t$ is distributed around a fixed and unobserved individual-specific mean, so $A_{i, t}=A_{i}+\varepsilon_{i, t}^{a}$. Individuals learn $A_{i, t}$ after each year, but cannot separate $A_{i}$ from $\varepsilon_{i, t}^{a}$. If $\varepsilon_{i, t}^{a}$ is mean zero and serially uncorrelated, then $E_{t}\left[A_{i, t}\right]=E_{t}\left[A_{i}\right]$. Also, since I have assumed risk neutrality, the variance of $\varepsilon_{i, t}^{a}$ has no impact on expected utility or decisions, so can be ignored.

${ }^{19}$ Todd R. Stinebrickner and Ralph Stinebrickner (2009) have direct evidence that students are over-confident about their likely performance in college. How students form expectations about college is ripe area for future research.

${ }^{20}$ This is an approximation of the normal learning model, which imposes that $\gamma_{X t}=\left(\frac{1 / \sigma_{a}^{2}}{1 / \sigma_{a}^{2}+(t-1) / \sigma_{g}^{2}}\right)$, where $\sigma_{a}^{2}$ is the variance of $A_{i}$ and $\sigma_{g}^{2}$ is the variance of $\left(g_{i, t}-A_{i}\right)$. Instead of imposing that the learning process follow this structure, I estimate $\gamma_{X t}$ and the variance of the residual $g_{i, t}-E_{t}\left[A_{i}\right]$ as parameters.
} 
ability, I specify that $\alpha_{m, j}$ and $\gamma_{m}$ come from a mass point distribution which describe the ability and schooling preferences of $M$ different types of individuals. ${ }^{21} \gamma_{m}$ measures the unobserved academic aptitude of people of "type" $m$ and $\alpha_{m, j}$ is their preference for school of type $j$. Type is known to the individual throughout, but is unknown to the econometrician. Essentially, the specification permits the intercepts of academic performance and of indirect utility to each take on three different values, corresponding to the three unobserved types. As a special case, I will also estimate models with no unobserved heterogeneity, which assumes that all correlation between preference for school and academic aptitude are captured linearly through $\alpha_{A} E_{t}\left[A_{i}\right] . \bar{u}_{i, j, 1}^{S}(\cdot)$ represents the non-stochastic component of the indirect utility of attending school. Individuals know baseline characteristics $\left(X_{i}\right)$ as well as the first period shocks $\left(\varepsilon_{i, 2,1}^{s}, \varepsilon_{i, 4,1}^{s}, \varepsilon_{i, 1}^{w}\right)$ when making the initial enrollment decision, but learn future shocks and grade outcomes only after enrolling. All other parameters of the model are known to the individual throughout.

At each period $t$, the individual maximizes the expected discounted value of lifetime utility by choosing whether to discontinue schooling and receive $u_{i, t}^{w}$ or continue school for at least one more year. Solving the model consists of finding the value functions for each alternative at each point in time: $V_{i, 2, t}^{s}, V_{i, 4, t}^{s}$, and $V_{i, t}^{w}$. These value functions take the following form:

$$
\begin{aligned}
V_{i, t}^{w} & =u_{i, t}^{w} \\
V_{i, j, t}^{s} & =u_{i, j, t}^{s}+\beta E\left[\max \left\{V_{i, t+1}^{w}, V_{i, j, t+1}^{s}\right\}\right]
\end{aligned}
$$

The decision problem can be solved for each individual by backwards recursion. In order to get a closed form solution for the $E[\max \{.,\}$.$] term, I assume these shocks are drawn$ from an Extreme Value Type I distribution with location and scale parameters zero and $\tau$, respectively. The derivation of these value functions is contained in Web Appendix C.

A key model simplification is that the labor market is an absorbing state; I do not explicitly model choices and outcomes after initial labor market entry. While it is possible to re-enter college after leaving, doing so is not the norm and those that do seldom earn a B.A. degree. In my sample, the fraction of students who return in the year after labor market entry is $16 \%, 20 \%, 29 \%$, and $27 \%$ for those who enter the labor market in year one to four, respectively. Approximately three quarters of B.A. recipients never have a period of delay or non-enrollment. While the model does not preclude people from re-enrolling, I have not modeled this decision explicitly and the expected financial gains of being able to return to school is embedded in the estimated lifetime income attached to each absorbing state. Importantly, these estimated payoffs ignore the option value created by the opportunity to re-enroll after dropping out. A more general model would explicitly model re-enrollment by setting $V_{i, t}^{w}=u_{i, t}^{w}+\beta E\left[\max \left\{V_{i, t+1}^{w}, V_{i, t+1}^{s}\right\}\right]$. I return to the implications of this simplification for my estimates of the option value in a later

\footnotetext{
${ }^{21}$ The use of a mass-point distribution to approximate the distribution of preferences known to the agent but unknown to the econometrician is discussed by Heckman and Burton Singer (1984) and is widely used in dynamic structural work such as Keane and Wolpin (1997) and Zvi Eckstein and Wolpin (1999). Here I estimate models with up to three points of support.
} 
section and discuss this and other desirable extensions in Web Appendix D.

\section{Interpretation of parameters}

The indirect utility functions $\left\{V_{i, j, t}^{s}, V_{i, t}^{w}\right\}_{t=1}^{t=4}$ provide expressions for the relative desirability of entering the labor market or continuing in school at time $t$. This relative value depends on a number of primitive parameters. The direct and opportunity costs as well as financial returns are captured in the terms Cost $_{i, t}$ and Income $_{i, t}$. Their importance to educational decisions have been the topic of much examination.

Less frequently studied is the contribution of expected academic ability to enrollment and continuation decisions. This is captured by $\alpha_{A}$ and the parameters of the grade function. Throughout I interpret the parameter $\alpha_{A}$ as quantifying the effect of collegiate aptitude on the expected psychic costs (or benefits) from school attendance. However, if students with higher grades also have higher returns, an alternative interpretation is that $\alpha_{A} E_{t}\left[A_{i}\right]$ captures expected individual-specific returns to each year of schooling. In this view, individuals who receive favorable ability signals update their belief about their individual returns to education, and thus remain in school. ${ }^{22}$ I am not able to distinguish between these two possible mechanisms with only data on grades and schooling decisions. Since psychic schooling costs (or benefits) are experienced immediately and individual-specific returns are more distant (potentially less salient), it is plausibly more natural to model learning about the former than the latter. Regardless, the estimated option value does not depend on which mechanism is dominant. ${ }^{23}$

The value of enrollment is also influenced by the amount of uncertainty and the speed at which it is revealed, as parameterized by $\tau$ and $\left\{\gamma_{X t}, \sigma_{G t}\right\}_{t=1}^{t=4}$. If $\tau$ is high, then preference shocks have a high variance, which increases the value of college enrollment and continuation. Future decisions take these preference shocks into account, so a greater variance increases the likelihood that either the schooling or work shock will be high, thus increasing the option value.

Option value decreases with the variance of grade shocks $\left(\sigma_{G t}\right)$. Since grades provide a noisy signal of unobserved ability (which influences utility through academic performance), greater variance decreases the signal value of grade realizations and thus the option value created by the ability to learn about aptitude through grades. If grades provided no signal value (either because they were completely random or because there is no uncertainty about ability), the value of enrollment would be diminished.

The temporal nature of learning about ability is parameterized by $\left\{\gamma_{X t}\right\}_{t=1}^{t=4}$. If academic ability is learned quickly, then $\gamma_{X t}$ should decline rapidly at first then level off. If subsequent grade shocks continue to provide new information about ability, $\gamma_{X t}$ should continue to decline throughout college. The normal learning model imposes that $\gamma_{X t}$

\footnotetext{
${ }^{22}$ Note that this interpretation requires that people with higher grades have higher returns to schooling, not just a higher level of earnings.

${ }^{23}$ Appropriate policy interventions do depend on the mechanism: providing students with more information about how much they will enjoy (or dislike) college would be inappropriate if the learning is mostly about individual-specific returns.
} 
follow a specific decreasing pattern over time.

\section{Estimation and identification}

The parameters of the model are estimated with full information maximum likelihood using data on the enrollment decisions, academic performance, and baseline characteristics of a panel of individuals. With no unobserved heterogeneity, individual $i$ 's contribution to the likelihood function is $L_{i}=L_{i}^{1} \cdot L_{i}^{2} \cdot L_{i}^{3}$, where:

Period 1: $\quad L_{i}^{1}=\operatorname{Pr}\left(S_{i, 2,1}=1\right)^{S_{i, 2,1}} \operatorname{Pr}\left(S_{i, 4,1}=1\right)^{S_{i, 4,1}} \operatorname{Pr}\left(S_{i, 1}=0\right)^{1-S_{i, 1}}$

$$
\begin{aligned}
& \text { Periods } 2 \text { to } 4: L_{i}^{2}=\prod_{t=2}^{4} \operatorname{Pr}\left(S_{i, t}=1\right)^{S_{i, t}} \operatorname{Pr}\left(S_{i, t}=0\right)^{1-S_{i, t}} \\
& \text { Grades } \quad: \quad L_{i}^{3}=\prod_{t=1}^{4} \operatorname{Pr}\left(g_{i, t}\right)
\end{aligned}
$$

where $S_{i, 2,1}$ and $S_{i, 4,1}$ indicate pathway choice in period 1 and $S_{i, t}$ is an indicator for enrollment in either type of school during period $t$. With the extreme value assumption on the preference shocks (which are unobserved to the econometrician), choice probabilities take the familiar logit form and the likelihood of grade outcomes given by the normal probability density function.

When unobserved (to the econometrician) heterogeneity is included, the likelihood contribution of individual $i$ must be integrated over the joint distribution of $\gamma_{m}$ and $\alpha_{m, j}$. Since this distribution is assumed to have $M$ mass points, the type-specific likelihood contribution must be summed over the $M$ possible types, weighted by the probability of being each type.

$$
L_{i}=\sum_{m=1}^{M} p_{m} L_{i m}
$$

where $p_{m}$ is the probability of being "type" $m$, which is a parameter to be estimated.

With no heterogeneity, there are 16 parameters to estimate: five in the utility function $\left(\alpha_{0,2}, \alpha_{0,4}, \alpha_{A}, \alpha_{D}, \tau\right)$ and eleven in the grade equations $\left(\gamma_{0}, \gamma_{G}, \gamma_{T}, \gamma_{P}, \sigma_{G 1}, \gamma_{X 2}\right.$, $\left.\sigma_{G 2}, \gamma_{X 3}, \sigma_{G 3}, \gamma_{X 4}, \sigma_{G 4}\right)$. Unobserved heterogeneity adds four parameters $\left(\alpha_{m, 2}, \alpha_{m, 4}, \gamma_{m}, p_{m}\right)$ for each additional type.

The parameters in the utility function $\left(\alpha_{0,2}, \alpha_{0,4}, \alpha_{A}, \alpha_{D}\right)$ are identified from the educational choices up to the scale parameter $\tau$. For example, the difference in enrollment rates between individuals with high expected grades and low expected grades but all else equal identifies the ratio $\alpha_{A} / \tau$. Since utility is in dollar units, $\tau$ is identified from variation in Tuition $_{i, t}$ and Income $_{i, t}$ across individuals and across periods. Holding all other variables constant, the estimate of $\tau$ is the magnitude of preference shocks that is needed to rationalize the proportions of people dropping out in each year, given the financial costs and benefits from doing so and the parametric distribution assumed on the shocks. For instance, if the financial return to completing a fourth year of college is much higher 
than completing the third year, then more people should drop out before the third year than the fourth. The magnitude of this enrollment difference identifies $\tau$ - if the dropout rates are similar then the variance of preference shocks must be high ( $\tau$ must be large) to rationalize the data. Cross-state tuition differences contribute to the identification of $\tau$ in the same way. It should be noted that the estimate of $\tau$ will be affected by any bias in the estimate of the return to each year of schooling. If the least squares estimated return to each year of school is biased upwards by unobserved factors, then the estimate of $\tau$ will also be overstated. However, most IV and twins estimates suggest that ability bias in OLS estimates is not too severe. ${ }^{24}$ Similarly, if the value of school continuation relative to labor market entry is overstated due to the omission of the re-enrollment option value from the latter, then the estimate of $\tau$ will be overstated. Upward bias in the estimate of $\tau$ will result in an upward bias in the estimated option value.

The parameters of the grade function are identified primarily from the grade outcomes in the typical manner, though the educational choices also help identify these parameters.

Parameters associated with unobserved heterogeneity are identified by common behavior which is contrary to the model. For instance, there may be individuals with poor academic performance but who still persist to graduation due to unmodeled parental pressure. If there are a sufficient number of similar individuals, then a model that permits for this type of behavior will fit the data better (i.e., have a higher likelihood). In practice, it is difficult to identify the discount factor $\beta$ separately from $\tau$. In the current specification, I fix $\beta$ at $0.95 .{ }^{25}$ As a robustness check, I also permit $\beta$ to vary between the enrollment and continuation decisions.

\section{Estimation Results}

\section{A. Parameter estimates}

Table 1 provides estimates of the structural parameters. Columns (1) and (2) provide estimates from a base model with no learning about academic aptitude while columns (3) and (4) provide estimates from the full model described above. Both models are estimated with and without allowing for up to three points of unobserved heterogeneity. Standard errors were computed by taking the inverse of the numerical Hessian at the estimated parameter values.

In the model without learning, expectations about grade realizations are based exclusively on baseline characteristics and type, so $E_{t}\left[A_{i}\right]=E\left[A_{i} \mid X_{i}\right.$, Type $]$ for all $t$. The parameter estimates all have the expected signs and are statistically significant. Since utility is in units of dollars, these estimates are immediately interpretable as the dollar value (in $\$ 100,000$ ) associated with a one-unit change in the independent variable. With no unobserved heterogeneity or learning (column (1)), the estimates imply that four-year colleges have amenities valued at $\$ 32,300$ over two-year colleges. Expecting to do well

\footnotetext{
${ }^{24}$ See Card (1999) for a review.

${ }^{25}$ I have estimated the model with $\beta=0.90$ and the results are qualitatively similar. The estimate of the dollar value of the option value decreases by one third reflecting a decrease in the estimated scale parameter $\tau$, but the importance of option value relative to the value of enrollment and welfare is unchanged.
} 
Table 1 -Estimates of Structural Parameters

\begin{tabular}{|c|c|c|c|c|}
\hline & \multicolumn{2}{|c|}{ No Learning } & \multicolumn{2}{|c|}{ Learning } \\
\hline & One type & Three types & One type & Three types \\
\hline Utility parameters & (1) & $(2)$ & (3) & (4) \\
\hline Constant (2yr) & $\begin{array}{l}-2.911 \\
(0.150)\end{array}$ & $\begin{array}{l}-4.346 \\
(0.442)\end{array}$ & $\begin{array}{c}-2.569 \\
(0.121)\end{array}$ & $\begin{array}{l}-3.187 \\
(0.378)\end{array}$ \\
\hline Constant (4yr) & $\begin{array}{l}-2.588 \\
(0.137)\end{array}$ & $\begin{array}{c}-3.765 \\
(0.391)\end{array}$ & $\begin{array}{l}-2.220 \\
(0.105)\end{array}$ & $\begin{array}{l}-2.845 \\
(0.332)\end{array}$ \\
\hline$E[A i]$ & $\begin{array}{c}0.707 \\
(0.049)\end{array}$ & $\begin{array}{c}1.242 \\
(0.161)\end{array}$ & $\begin{array}{c}0.591 \\
(0.039)\end{array}$ & $\begin{array}{c}1.009 \\
(0.154)\end{array}$ \\
\hline Distance (100) & $\begin{array}{c}0.121 \\
(0.034)\end{array}$ & $\begin{array}{c}0.277 \\
(0.074)\end{array}$ & $\begin{array}{c}0.139 \\
(0.034)\end{array}$ & $\begin{array}{c}0.220 \\
(0.065)\end{array}$ \\
\hline Tau & $\begin{array}{c}0.511 \\
(0.022)\end{array}$ & $\begin{array}{c}0.780 \\
(0.074)\end{array}$ & $\begin{array}{c}0.513 \\
(0.023)\end{array}$ & $\begin{array}{c}0.642 \\
(0.070)\end{array}$ \\
\hline Grade parameters & & & & \\
\hline Constant (gpa) & $\begin{array}{c}1.192 \\
(0.056)\end{array}$ & $\begin{array}{c}0.835 \\
(0.102)\end{array}$ & $\begin{array}{c}0.802 \\
(0.072)\end{array}$ & $\begin{array}{c}0.659 \\
(0.087)\end{array}$ \\
\hline High school GPA & $\begin{array}{c}0.383 \\
(0.019)\end{array}$ & $\begin{array}{c}0.394 \\
(0.026)\end{array}$ & $\begin{array}{c}0.436 \\
(0.025)\end{array}$ & $\begin{array}{c}0.523 \\
(0.029)\end{array}$ \\
\hline AFQT & $\begin{array}{c}0.411 \\
(0.039)\end{array}$ & $\begin{array}{c}0.702 \\
(0.082)\end{array}$ & $\begin{array}{c}0.581 \\
(0.057)\end{array}$ & $\begin{array}{c}0.695 \\
(0.072)\end{array}$ \\
\hline Parent BA & $\begin{array}{c}0.206 \\
(0.017)\end{array}$ & $\begin{array}{c}0.297 \\
(0.033)\end{array}$ & $\begin{array}{c}0.281 \\
(0.026)\end{array}$ & $\begin{array}{c}0.336 \\
(0.033)\end{array}$ \\
\hline $\mathrm{E}[\mathrm{A} \mid \mathrm{X}]$ period 2 & & & $\begin{array}{c}0.482 \\
(0.030)\end{array}$ & $\begin{array}{c}0.528 \\
(0.034)\end{array}$ \\
\hline$E[A \mid X]$ period 3 & & & $\begin{array}{c}0.319 \\
(0.038)\end{array}$ & $\begin{array}{c}0.343 \\
(0.046)\end{array}$ \\
\hline$E[A \mid X]$ period 4 & & & $\begin{array}{c}0.188 \\
(0.046)\end{array}$ & $\begin{array}{c}0.206 \\
(0.057)\end{array}$ \\
\hline SD(gpa) & $\begin{array}{c}0.645 \\
(0.008)\end{array}$ & $\begin{array}{c}0.478 \\
(0.007)\end{array}$ & & \\
\hline SD(gpa year 1 ) & & & $\begin{array}{c}0.657 \\
(0.014)\end{array}$ & $\begin{array}{c}0.617 \\
(0.016)\end{array}$ \\
\hline SD(gpa year 2) & & & $\begin{array}{c}0.534 \\
(0.013)\end{array}$ & $\begin{array}{c}0.521 \\
(0.013)\end{array}$ \\
\hline SD(gpa year 3) & & & $\begin{array}{c}0.526 \\
(0.014)\end{array}$ & $\begin{array}{c}0.520 \\
(0.014)\end{array}$ \\
\hline SD(gpa year 4) & & & $\begin{array}{c}0.547 \\
(0.016)\end{array}$ & $\begin{array}{c}0.545 \\
(0.016)\end{array}$ \\
\hline Type-specific parame & & & & \\
\hline Constant (gpa) - T2 & & $\begin{array}{c}0.634 \\
(0.024)\end{array}$ & & $\begin{array}{c}0.256 \\
(0.088)\end{array}$ \\
\hline Constant (2yr) - T2 & & $\begin{array}{c}0.124 \\
(0.290)\end{array}$ & & $\begin{array}{c}0.603 \\
(0.196)\end{array}$ \\
\hline Constant (4yr) - T2 & & $\begin{array}{c}-0.244 \\
(0.185)\end{array}$ & & $\begin{array}{l}-2.387 \\
(0.519)\end{array}$ \\
\hline Probability T2 & & $\begin{array}{c}0.174 \\
(0.022)\end{array}$ & & $\begin{array}{c}0.075 \\
(0.011)\end{array}$ \\
\hline Constant (gpa) - T3 & & $\begin{array}{c}-0.889 \\
(0.042)\end{array}$ & & $\begin{array}{c}-0.536 \\
(0.067)\end{array}$ \\
\hline Constant (2yr) - T3 & & $\begin{array}{c}-0.201 \\
(0.245)\end{array}$ & & $\begin{array}{c}-1.646 \\
(0.496)\end{array}$ \\
\hline Constant (4yr) - T3 & & $\begin{array}{c}0.271 \\
(0.088)\end{array}$ & & $\begin{array}{c}-0.441 \\
(0.120)\end{array}$ \\
\hline Probability T3 & & $\begin{array}{c}0.359 \\
(0.030)\end{array}$ & & $\begin{array}{c}0.625 \\
(0.040)\end{array}$ \\
\hline Observations & 2055 & 2055 & 2055 & 2055 \\
\hline $\operatorname{lnL}$ (total) & 6328 & 5844 & 5888 & 5719 \\
\hline
\end{tabular}

Note: Utility is in units of $\$ 100,000$. Income specification (1) from Web Appendix Table B1 was used to generate counterfactual income estimates. Standard errors (in parentheses) were calculated from the inverse of the numerical Hessian. Specifications (3) and (4) uses seventeen GPA categories for Emax approximation $(0.0,0.25,0.50, \ldots, 4.0)$. 
in school is also valuable. Each additional grade point (e.g. going from a C-student to a B-student) is equivalent to $\$ 70,700$. Living 100 miles from a college is equivalent to paying an additional $\$ 12,100$ in tuition. A key parameter is $\tau$, which parameterizes the variance of the preference shocks. At the estimated parameters, the preference shocks have a standard deviation of $\$ 65,500\left(=\tau \frac{\Pi}{\sqrt{6}}\right)$. As expected, the grade parameter estimates show a strong positive correlation between academic performance and baseline characteristics such as academic performance in high school, AFQT test scores, and parent's education.

The estimate of $\alpha_{A}$ in column (1) could be biased if people with high academic ability also have a stronger preference for attending school, independent of the causal effect of aptitude on schooling ease. Column (2) addresses this concern by allowing for several different "unobserved types," each with an arbitrary correlation between schooling preference and academic aptitude. Permitting unobserved heterogeneity improves model fit considerably. Relative to type 1 individuals, type 2 individuals (17\% of sample) are higher ability $\left(\gamma_{\text {type } 2}>0\right)$, but have a stronger dislike of 4-year colleges $\left(\alpha_{\text {type } 2}^{S 4}<0\right)$ and are neutral to two-year colleges. These individuals can be thought of as good students from disadvantaged families. By contrast, type 3 individuals (36\%) are lower ability $\left(\gamma_{\text {type } 3}<0\right)$, have a stronger preference for 4-year colleges $\left(\alpha_{\text {type3 }}^{S 4}>0\right)$ and dislike two-year colleges $\left(\alpha_{\text {type } 2}^{S 2}<0\right)$, though this latter effect is not statistically significant. Incorporating unobserved heterogeneity does not qualitatively change the other parameter estimates. It does, however, diminish the estimated importance of earnings to schooling decisions, which increases the estimated deviation of the preference shocks to $\$ 100,000$. Consequently, the magnitude of the other parameter estimates also increases. Interestingly, the relationship between expected academic ability and enrollment probabilities ( $\alpha_{A} / \tau$ ) changed little, increasing from 1.4 to 1.6 when unobserved heterogeneity is permitted. The estimated variance of the grade shocks decreases because a greater share of the performance variance is captured by baseline characteristics (including type).

Columns (3) and (4) present estimates from the full learning model presented in Section II. The parameter estimates are very similar to estimates from the no-learning model, both qualitatively and quantitatively. With learning, individuals estimate future academic performance by calculating a weighted average of performance predicted with baseline characteristics (including type) and cumulative grade point average, where the weights $\left(\gamma_{x 2}, \gamma_{x 3}\right.$, and $\left.\gamma_{x 4}\right)$ are parameters to be estimated. The normal learning model predicts that the weight placed on baseline characteristics should decrease with $t$ ( $\gamma_{x 1}$ is normalized to one), as should the residual grade variance $\left(\sigma_{g t}\right)$. The estimates in column (3), which do not control for unobserved heterogeneity, support this implication of the normal learning model. The best predictor of year-two grades weighs baseline characteristics and first-year grades approximately equally (48\% vs. 52\%). Fourth-year grades, however, are best predicted by placing only $19 \%$ of the weight on baseline characteristics and $81 \%$ on three-year cumulative grade point average.

Due to unobserved heterogeneity, however, these estimates can overstate the amount of learning taking place. $E\left[A_{i} \mid X_{i}\right]$ may not fully capture all information about future academic performance available to individuals, so the increasing weight placed on $\mathrm{cu}-$ 
mulative academic performance may simply capture the revelation of private information to the econometrician. Column (4) addresses this concern (and the potential bias of $\alpha_{A} / \tau$ discussed earlier) by allowing for several different unobserved types, each with different levels of academic aptitude, known ex-ante, and preferences for two- and four-year school. The estimates in column (4), which allow for three different types, imply that learning about academic ability continues to occur through the end of college. Controlling for unobserved heterogeneity does not change the learning parameters much. ${ }^{26}$

The types identified in the learning model are slightly different than those revealed in the non-learning model. Relative to type 1, type 2 individuals ( $8 \%$ of the sample) have higher academic aptitude, greater-than-average preference for two-year colleges, and less preference for four-year colleges. Type 3 individuals $(63 \%)$ reflect students with poor academic aptitude who have lower than expected preference for two- and four-year schools. Accounting for unobserved heterogeneity again diminishes the importance of earnings which increases $\tau$ and the scale of most other parameters, though the relationship between expected academic ability and enrollment probabilities $\left(\alpha_{A} / \tau\right)$ changes little. The estimated deviation of the preference shocks is about $\$ 82,000$ in this preferred specification. The overall model fit also improves when unobserved heterogeneity is permitted. I now discuss model fit more directly.

\section{B. Model fit}

To examine model fit, I simulate the grade outcomes and educational choices of individuals in my estimation sample 100 times and compare the predicted outcomes to the actual observed outcomes. In this section I discuss simulations that use the preferred estimated parameter values, from model (4) from Table 1. In Web Appendix E, I also present fit for the models that do not incorporate unobserved heterogeneity and learning simultaneously (models (1) to (3) in Table 1). In general, the preferred specification provides a much better fit of the data than the simpler models. I examine model fit in two ways. First, I compare actual to predicted enrollment outcomes, including initial pathway choice, dropout, and college completion. This comparison is also done by demographic characteristics which are not explicitly incorporated in the model. I then examine the relationship between grade outcomes and subsequent enrollment decisions. It should be noted that if the model contained utility intercepts that differ over time, by school, and by academic performance, then the moments presented below would not constitute a true test of "fit." Such a fully saturated and calibrated model would fit the data perfectly. The model I employ is much more parsimonious, as I discuss below.

Figure 5 compares the predicted enrollment decisions to the actual decisions made by individuals in the estimation sample. Overall, the model predictions fit the distribution of actual enrollment decisions reasonably well considering how unsaturated the model is. Forty-five percent of individuals are predicted not to enroll, two percentage points

\footnotetext{
${ }^{26}$ These results assume that I have specified the information set used by individuals correctly. If students possess information about future grades beyond that modeled here, these estimates overstate the extent of uncertainty and learning and understate the extent of hetergeneity. The methods presented in Cuhna, Heckman, and Navarro (2005) could be used to distinguish between these two sources of variability.
} 


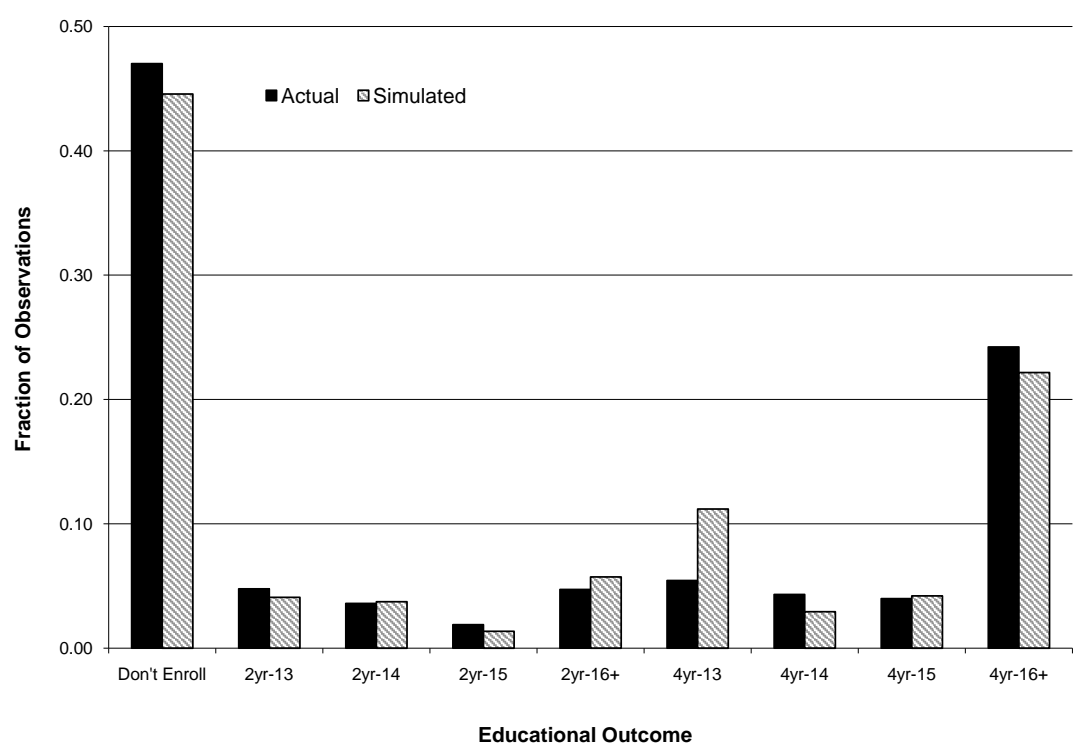

Figure 5. Actual vs. Simulated Educational Outcomes

Note: To generate simulated outcomes, the unobserved type, grade and preference shocks, and choices of each observation is simulated 100 times, assuming that individuals follow the full model described in the text with parameter values equal to those in specification (4) of Table 1.

below the actual share. Consequently, enrollment in four-year colleges is over-predicted by three percent. The fraction of individuals enrolling in two-year colleges is identical between actual and predicted. The goodness of initial enrollment decision fit is not surprising since the model includes separate constants for two- and four-year schools in the utility function $\left(\alpha_{0, j}\right)$. If the parameters were estimated using only the initial enrollment decision, these shares would fit exactly.

The fit of dropout behavior following initial enrollment decision is a better test of the ability of the model to predict behavior. Since the utility intercepts do not vary over time, predicted differential dropout between different periods is driven entirely by between-period differences in the financial returns (lifetime earnings gain minus costs) and changes in expected academic performance $\left(E_{t}\left[A_{i}\right]\right)$. Figure 6 depicts the fraction of two- and four-year enrollments who drop out in each year or graduate. There are two primary discrepancies between the model predictions and actual outcomes. First, the model slightly underpredicts the fraction of people beginning at community college that drop out after one or three years and consequently over-predicts completion. The second discrepancy is that the model over-predicts dropout after the first year among people that start at a four-year college and consequently underpredicts four-year college graduation.

Figure 7 compares actual and predicted enrollment shares by whether students come from a high- or low-income family. Family income does not enter the model at all, so this 


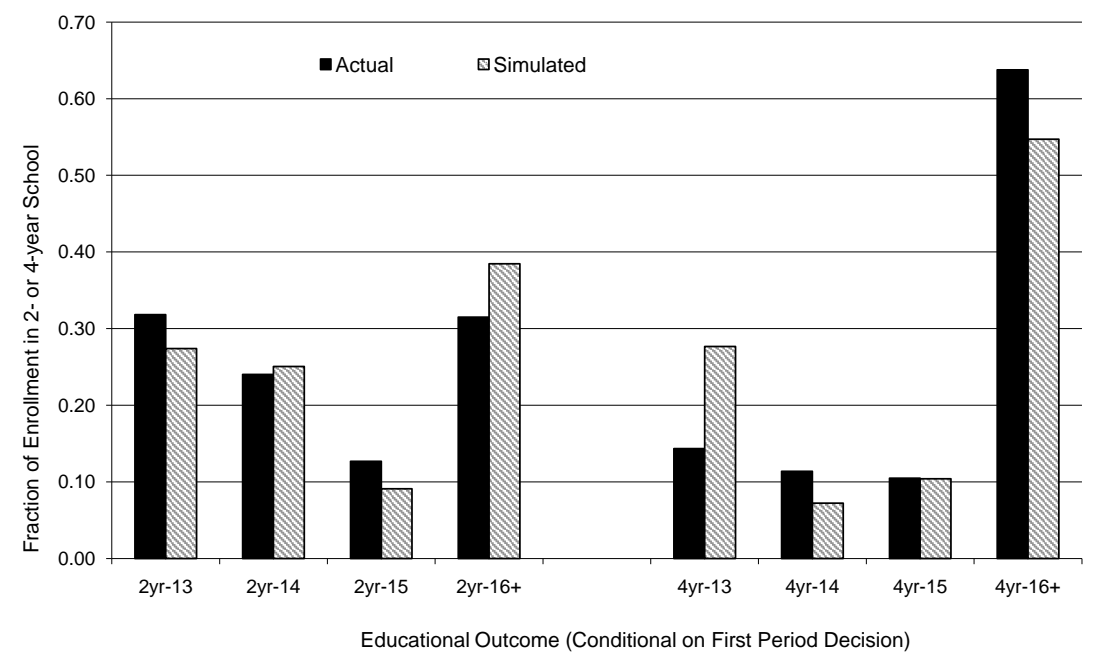

Figure 6. Actual vs. Simulated Outcomes Conditional on EnRollment

Note: To generate simulated outcomes, the unobserved type, grade and preference shocks, and choices of each observation is simulated 100 times, assuming that individuals follow the full model described in the text with parameter values equal to those in specification (4) of Table 1. 


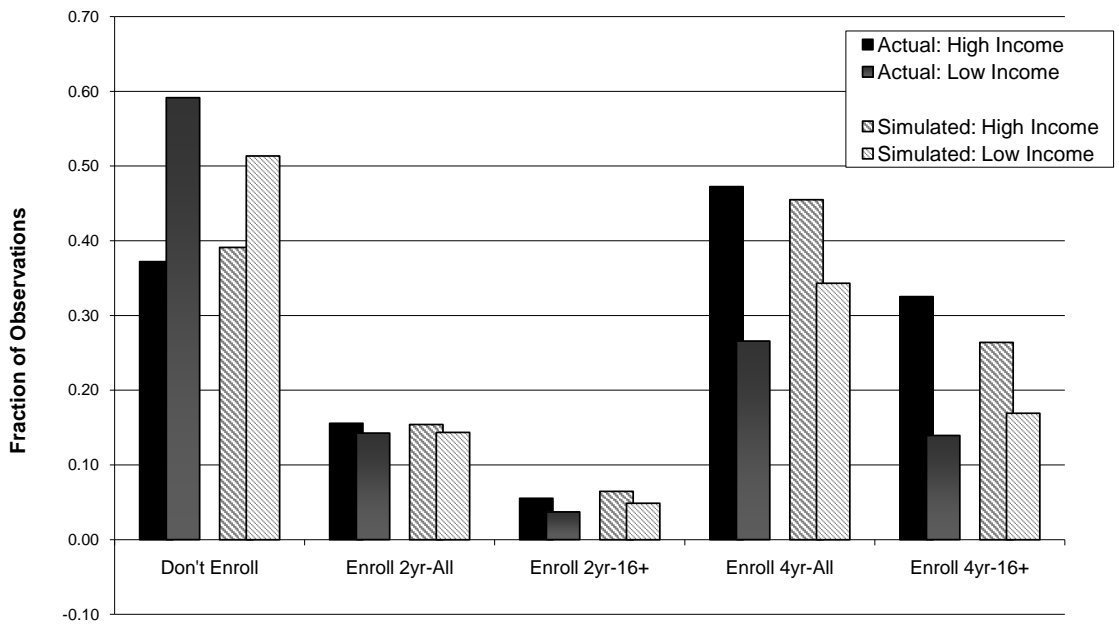

Educational Outcome

Figure 7. Model Fit of Educational Outcome Differentials by Family Income

Note: To generate simulated outcomes, the unobserved type, grade and preference shocks, and choices of each observation is simulated 100 times, assuming that individuals follow the full model described in the text with parameter values equal to those in specification (4) of Table 1.

is a pretty strong test of model fit. Any correlation between family income and enrollment outcomes must operate through the correlation between family income and the modeled background characteristics (high school performance, AFQT, and parental education). Additionally, these characteristics do not enter individuals' preferences for school directly. Higher parental education, for instance, increases academic aptitude, which in turn makes schooling more desirable. Higher parental education also increases predicted lifetime income, which reduces individuals' sensitivity to schooling costs. Nonetheless, the model still captures several important features of the data, namely the strong positive correlation between family income, college enrollment, and degree completion.

Enrollment decisions and grades are related for several reasons. First, students with adverse baseline characteristics (e.g., poor grades in high school) have low expected college aptitude, which increases the disutility of school. Consequently, students with low expected academic performance will be less likely to enroll and more likely to drop out if they do enroll. Second, if students learn about the desirability of college through their grades, then students who persist to graduation will have consistently received high grades while those who dropped out will have received low grades. Figure 8 displays the actual and simulated fraction of students that complete their fourth year by their first-year grade point average. The overall slope and curvature of the grade-graduation relationship is matched very closely. Like the actual data, predicted completion is increasing most 


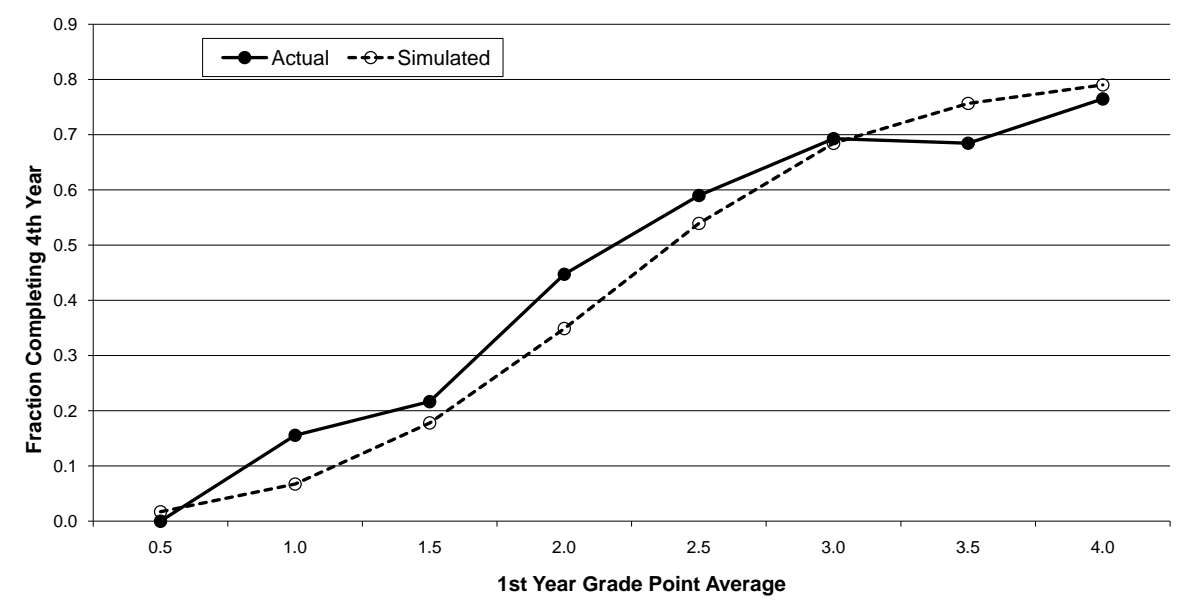

Figure 8. Actual vs. Simulated Graduation Rates by 1St Year GPA

Note: To generate simulated outcomes, the unobserved type, grade and preference shocks, and choices of each observation is simulated 100 times, assuming that individuals follow the full model described in the text with parameter values equal to those in specification (4) of Table 1.

quickly in the middle grade span, where grade signals are expected to be most influential.

\section{Discussion of estimates and fit}

To summarize, the parameter estimates suggest that uncertainty is an important feature of postsecondary schooling outcomes. The preferred estimates (column (4) from Table 1) indicate that the deviation of unanticipated shocks to the relative preference for enrollment and labor market entry is equivalent to $\$ 82,300$ in lifetime earnings. These shocks have the same order of magnitude as the incremental gain from completing a college degree. Thus, unanticipated preference shocks are an important determinant of educational outcomes. It should be noted that the model assumes that individuals face no credit constraints. My specification does not permit me to distinguish between large shocks and small shocks whose effects are magnified by credit constraints. My estimates reflect the combination of these two factors. ${ }^{27}$ The estimates also suggest that students learn about their ex-ante unknown academic aptitude through college grades. Lastly, the estimates suggest that academic aptitude does predict enrollment outcomes and that much of the relationship between family background and schooling outcomes can be captured through the effect of background on academic performance.

\footnotetext{
${ }^{27}$ Incorporating credit constraints would require a different structural model. Stephen V. Cameron and Heckman (2001) use such a model and conclude that long-run factors associated with family background, not short-term credit constraints, explain much of the observed racial disparity in college education.
} 
Predictions from simulations using the estimated model parameters do match many features of the actual data on enrollments and grade outcomes. The overall distributions of predicted and actual outcomes is roughly similar and the model captures several main features of the relationship between grade outcomes and enrollment decisions. Importantly, the model also replicates educational differences by background characteristics, despite the strong restriction that they operate entirely through expected academic performance.

\section{The Importance of Option Value}

In this section, I estimate the option value created by the ability of students to make educational decisions sequentially and in response to new information. To do this, I treat the estimated structural model as the actual data generating process and simulate educational choices and welfare under alternative assumptions about individuals' information set. ${ }^{28}$ In the static model, I simulate outcomes when individuals are restricted to commit to educational choices before enrolling in college. They base their decision only on information available before college enrollment: baseline characteristics (high school GPA, AFQT, parent education, and type), predicted lifetime earnings, direct tuition and commuting costs, and first-period shocks $\left(\varepsilon_{i, 2,1}^{s}, \varepsilon_{i, 4,1}^{s}, \varepsilon_{i, 1}^{w}\right)$. As a basis of comparison, I also simulate the choices and welfare in the first-best scenario, where individuals make decisions with perfect knowledge of all future shocks.

\section{A. Educational outcomes}

Figure 9 summarizes the importance of option value to educational decisions. The top panel plots the average number of years of college by expected academic ability, separately for the first-best full information (solid), baseline dynamic (dashed), and static (dotted) models. The static model predicts that education would be much more bifurcated if students were forced to commit ex-ante with limited information. People with low expected performance would get very little education while high ability students would get much more. Compared to the first-best outcome, this bifurcation reduces welfare because some ex-ante low-ability students should go to or graduate from college, while some higher ability students should not. Sequential decision-making permits individuals to come closer to the first-best outcome.

This can be seen more clearly in the middle and bottom panels, which plot the simulated enrollment and graduation rates by expected ability. These figures are the empirical analog to the right panels of Figure 3, where $E\left[A_{i} \mid X_{i}, T y p e\right]$ is analogous to $\varepsilon_{i, 1}$. Option value increases the enrollment rates of all individuals, particularly those in the middle who are on the enrollment margin in the static model. Many of these individuals would choose to enroll if they knew their shocks with certainty but would not if they

\footnotetext{
${ }^{28}$ To implement the simulations, I first replicate each observation 100 times. For each of these simulated observations, I then draw preference and grade shocks from the appropriately scaled EV(1) and normal distributions and assign an unobserved "type" based on the estimated probabilities. The optimal choices for each individual are then computed by utility comparisons, incorporating these shocks.
} 
Panel A. Average Years of College by Expected Academic Ability

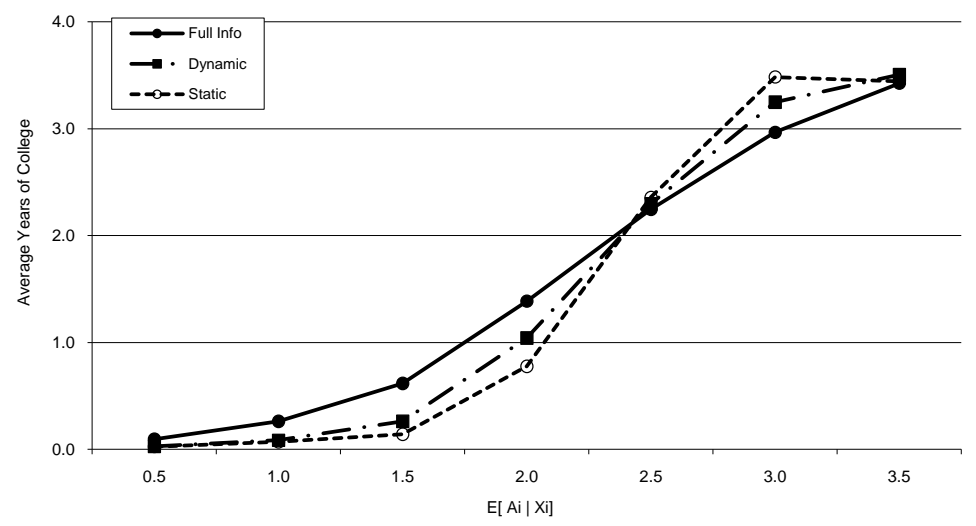

Panel B. Enrollment Rate by Expected Academic Ability

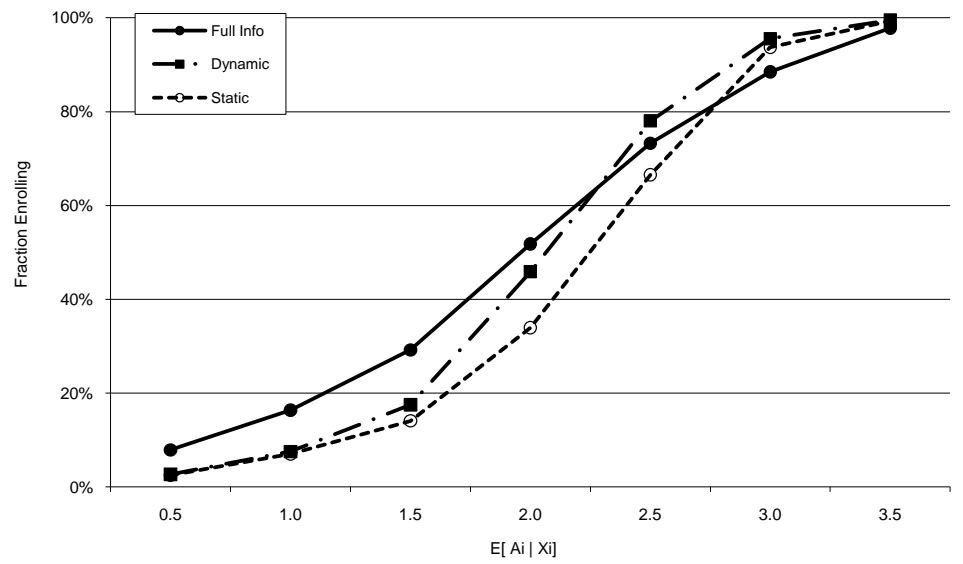

Panel C. Graduation Rate by Expected Academic Ability

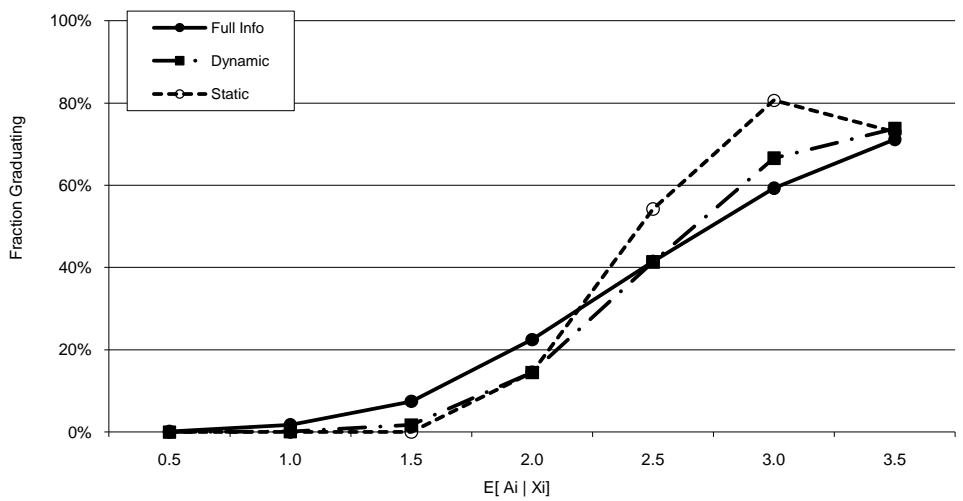

FiguRE 9. EFFECT OF UNCERTAINTY ON EDUCATIONAL OUTCOMES

Note: Notes: To generate simulated outcomes, the unobserved type, grade and preference shocks, and choices of each observation is simulated 100 times, assuming that individuals follow the static, full dynamic, or perfect information scenarios described in the text. Parameter values are assumed equal to those in specification (4) of Table 1. 
were forced to commit ex-ante. For low- to moderate-ability students, option value only slightly increases college completion. The biggest effect of option value on completion is to reduce it for high ability students. Some high-ability students expect to graduate so would commit to doing so ex-ante - but then learn that completion is undesirable and would prefer to drop out. Allowing them to do so reduces completion rates but improves their welfare.

\section{B. Quantifying option value}

Figure 10 quantifies the option value of college enrollment. The figure plots the average value of the opportunity to enroll in college by expected academic ability for the same three scenarios and is the empirical analog of Panel A in Figure 3. This value is zero for those who do not enroll. The value of the opportunity to enroll is increasing in expected ability both because enrollment increases with ability and because school is less costly for high ability people, so value conditional on enrollment is also increasing. The vertical distance between the solid and dotted lines represents individuals' total welfare loss from being forced to commit to an educational outcome ex-ante, compared to the first-best situation with full information. This loss is greatest for moderate-ability individuals. Since sequential decision making helps more individuals obtain their optimal level of education, it partially closes this welfare gap, as indicated by the dashed line. The difference between the dashed and dotted lines thus represents the value of the option to drop out whenever continuation turns out to be undesirable.

Table 2 summarizes the option value by expected ability category. On average, students would be willing to pay $\$ 14,900$ (in 1992 dollars) to maintain the ability to make enrollment decisions sequentially in response to new information. Given the precision of the parameter estimates, total option value is fairly precisely estimated with a $90 \%$ confidence interval of $\$ 11,400$ to $\$ 18,100 .{ }^{29}$ Consistent with the simple theoretical model, option value varies considerably with ability. Moderate-ability students, for whom educational outcomes are most uncertain, are willing to pay up to $\$ 25,000$, while the lowest ability students derive virtually no value from the option. The option is also worth less to higher ability students because their enrollment decisions do not depend on it. ${ }^{30}$

Table 2 also normalizes the option value in two ways. My estimates imply that option value accounts for $14 \%$ of the total value of the opportunity to enroll in college. For low to moderate ability students, this fraction is even higher. Option value also represents approximately one quarter of the welfare loss associated with moving from the full information to static scenarios.

Additional simulations are used to allocate the total option value into the years in which new information is learned. The first three years of college each provide new

\footnotetext{
${ }^{29}$ Since the option value is a highly nonlinear and complicated function of the parameters, I rely on simulations to compute the confidence intervals. Confidence intervals were computed by performing the option value simulation for 200 different draws of the parameter vector from its estimated distribution.

${ }^{30}$ These estimates are not directly comparable to those presented in Table 7 of Heckman, Lochner, and Todd (2006) because their model is one of exogenous dropout and their estimates include continuation value. That said, their estimate of the option value of college attendance is of a similar order of magnitude as that reported here.
} 


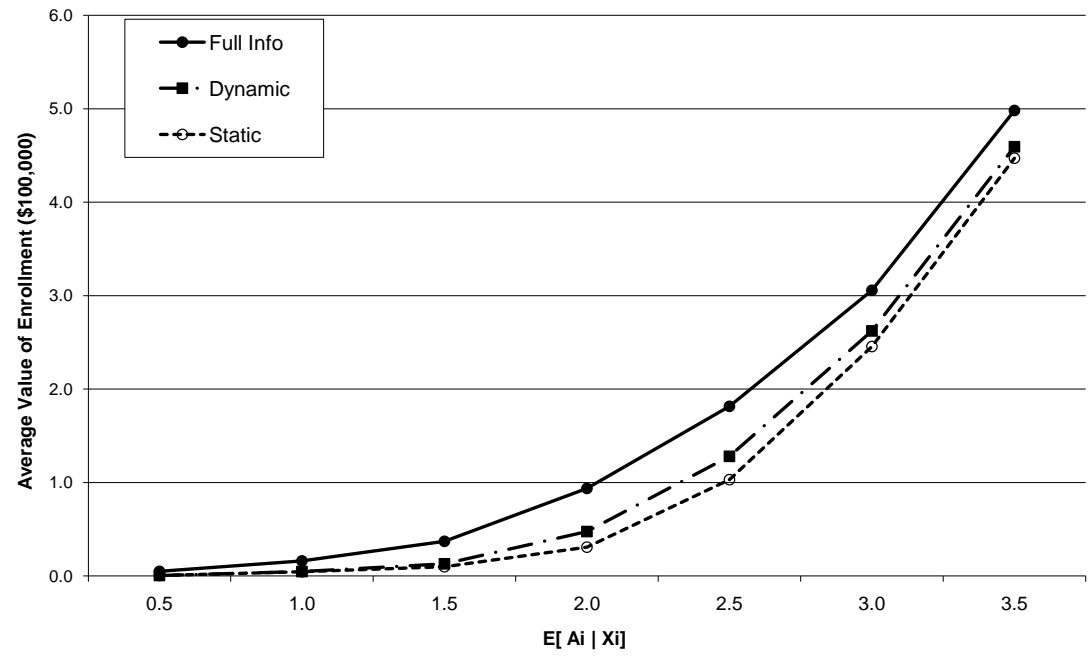

Figure 10. Average Value of College Enrollment Opportunity by Expected Academic Ability

Note: To generate simulated outcomes, the unobserved type, grade and preference shocks, and choices of each observation is simulated 100 times, assuming that individuals follow the static, full dynamic, or perfect information scenarios described in the text. Parameter values are assumed equal to those in specification (4) of Table 1.

Table 2-Estimated Option Value, By Expected Academic Ability

\begin{tabular}{|c|c|c|c|c|c|c|}
\hline \multirow[b]{2}{*}{$E\left[A_{i} \mid X_{i}\right]$} & \multicolumn{2}{|c|}{ Option value $(\$ 1,000)$} & \multicolumn{2}{|c|}{$\begin{array}{l}\text { Option value as percent of total } \\
\text { value of enrollment in dynamic } \\
\text { scenario }\end{array}$} & \multicolumn{2}{|c|}{$\begin{array}{l}\text { Option value as percent of } \\
\text { welfare loss between full } \\
\text { information and static scenarios }\end{array}$} \\
\hline & Estimate & $\begin{array}{c}90 \text { percent } \\
\text { confidence interval }\end{array}$ & Estimate & $\begin{array}{c}90 \text { percent } \\
\text { confidence interval }\end{array}$ & Estimate & $\begin{array}{c}90 \text { percent } \\
\text { confidence interval }\end{array}$ \\
\hline 1.0 & 0.3 & {$[0.21,1.67]$} & $7 \%$ & {$[4 \%, 19 \%]$} & $3 \%$ & {$[2 \%, 12 \%]$} \\
\hline 1.5 & 3.2 & {$[2.76,5.05]$} & $25 \%$ & {$[22 \%, 29 \%]$} & $12 \%$ & {$[11 \%, 17 \%]$} \\
\hline 2.0 & 16.8 & {$[13.39,20.48]$} & $35 \%$ & {$[31 \%, 38 \%]$} & $27 \%$ & {$[25 \%, 29 \%]$} \\
\hline 2.5 & 25.0 & {$[18.05,31.2]$} & $19 \%$ & {$[17 \%, 23 \%]$} & $32 \%$ & {$[29 \%, 34 \%]$} \\
\hline 3.0 & 16.6 & {$[12.67,21.27]$} & $6 \%$ & {$[5 \%, 8 \%]$} & $28 \%$ & {$[25 \%, 31 \%]$} \\
\hline 3.5 & 12.2 & {$[4.68,19.16]$} & $3 \%$ & {$[1 \%, 5 \%]$} & $24 \%$ & {$[9 \%, 32 \%]$} \\
\hline All & 14.9 & {$[11.43,18.09]$} & $14 \%$ & {$[12 \%, 16 \%]$} & $27 \%$ & {$[25 \%, 29 \%]$} \\
\hline
\end{tabular}

Note: For a given parameter vector, option value is calculated as the average welfare difference between the static and dynamic scenarios when the type, shocks, and choices of each observation is simulated 100 times. Confidence intervals are computed by performing this option value calculation for 200 different draws of the parameter vector from its estimated distribution. 
information about academic ability (in the form of grade signals) and the relative desirability of schooling and work $\left(\varepsilon_{i, 2, t}^{s}, \varepsilon_{i, 4, t}^{s}, \varepsilon_{i, t}^{w}\right)$. To do this decomposition, I simulate educational choices and welfare when individuals are restricted to commit to educational choices before enrolling in college (the static model discussed above), after the first year, after the second year, and after the third year (the baseline dynamic model). For moderate-ability students, the most valuable information is that which is learned in the first year of college, when the wisdom of their enrollment decision is most uncertain. Higher ability students derive relatively more value from information received later, when graduation decisions are made. Approximately $60 \%$ of the total option value derives from information learned in the first year, while the other two years account for about $20 \%$ each.

To summarize, the value of the option to drop out is considerable, particularly for moderate ability students who have the most uncertainty about their net benefit from schooling. The option to drop out has value both because it encourages more people to enroll, who may not want to if forced to commit ex-ante, and it because it permits dropout if graduation is undesirable among those who would commit to graduate exante. In aggregate, the former is greater than the latter. Furthermore, the majority of the aggregate option value comes from the information received in the first year of college.

\section{Robustness of option value estimates}

Table 3 explores the robustness of the option value estimates to basic changes in model specification. ${ }^{31}$ Specification (2) includes a persistent utility cost to transferring from a two-year to four-year school. The base model over-predicts the number of students that graduate with a four-year degree after starting at a two-year institution since the only incremental cost from transferring is higher tuition and further distance. Specification (3) allows the ability-learning process to differ between two-year and four-year students by permitting $\gamma_{X t}$ and the variance of the grade residual $\left(g_{i, t}-E_{t}\left[A_{i}\right]\right)$ to vary freely by initial sector. In specification (4), individuals are permitted to discount the continuation value at the time of enrollment differently than they do in subsequent years. Specification (5) combines all three of these changes simultaneously.

Transferring imposes a substantial utility cost on students starting at two-year schools, above and beyond the higher tuition and greater distance typically required by fouryear schools. Grades are more strongly and persistently correlated with background for four-year students than two-year students, though grades are more variable for the latter. Individuals put $17 \%$ less weight on continuation value when making enrollment decisions than when deciding whether to persist. While all three of these restrictions in the base model are rejected by the data, the estimated option value is remarkably robust across these different specifications. In particular, estimates of the importance of option value relative to the total value of the opportunity to enroll range from $12 \%$ (unrestricted model) to $19 \%$ (different learning process by sector only), with the base model falling in the middle (14\%). The dollar estimate of the option value is more heavily influenced

\footnotetext{
${ }^{31}$ Parameter estimates for these alternative specifications are contained in Web Appendix Table E1.
} 
Table 3-Estimated Option Value - Alternative Specifications

\begin{tabular}{|c|c|c|c|c|c|}
\hline & $\begin{array}{c}\text { Base model } \\
\text { (1) }\end{array}$ & $\begin{array}{l}\text { Persistent transfer } \\
\text { cost } \\
(2)\end{array}$ & $\begin{array}{c}\text { Different learning } \\
\text { process by sector } \\
\text { (3) }\end{array}$ & $\begin{array}{l}\text { Different weight on } \\
\text { continuation value at } \\
\text { enrollment } \\
\text { (4) }\end{array}$ & $\begin{array}{c}\text { Three changes } \\
\text { combined } \\
\text { (5) }\end{array}$ \\
\hline $\mathrm{E}[\mathrm{Ai} \mid \mathrm{Xi}]$ & \multicolumn{5}{|c|}{ Option value $(\$ 1,000)$} \\
\hline \multirow[t]{2}{*}{1.0} & 0.3 & 0.4 & 0.7 & 0.7 & 8.3 \\
\hline & {$[0.2,1.7]$} & {$[0.2,1.1]$} & {$[0.5,12.4]$} & {$[0.2,2.0]$} & {$[-2.2,10.8]$} \\
\hline \multirow[t]{2}{*}{1.5} & 3.2 & 3.7 & 5.4 & 4.8 & 11.6 \\
\hline & {$[2.8,5.1]$} & {$[2.7,4.8]$} & {$[4.7,42.8]$} & {$[3.6,6.7]$} & {$[7.3,18.2]$} \\
\hline \multirow[t]{2}{*}{2.0} & 16.8 & 17.5 & 30.5 & 18.6 & 61.5 \\
\hline & {$[13.4,20.5]$} & {$[13.4,20.3]$} & {$[23.0,78.0]$} & {$[13.9,21.8]$} & {$[37.2,86.6]$} \\
\hline \multirow[t]{2}{*}{2.5} & 25.0 & 26.6 & 41.1 & 24.5 & 44.2 \\
\hline & {$[18.1,31.2]$} & {$[20.6,31.6]$} & {$[32.0,65.4]$} & {$[18.0,31.1]$} & {$[28.4,63.3]$} \\
\hline \multirow[t]{2}{*}{3.0} & 16.6 & 15.6 & 25.1 & 17.8 & 28.0 \\
\hline & {$[12.7,21.3]$} & {$[11.4,19.4]$} & {$[19.9,40.0]$} & {$[13.4,23.4]$} & {$[20.2,39.8]$} \\
\hline \multirow[t]{2}{*}{3.5} & 12.2 & 7.7 & 18.8 & 13.9 & 62.2 \\
\hline & {$[4.7,19.2]$} & {$[3.9,10.6]$} & {$[7.2,31.6]$} & {$[7.6,22.5]$} & {$[32.6,82.7]$} \\
\hline \multirow[t]{2}{*}{ All } & 14.9 & 15.2 & 24.0 & 17.3 & 44.6 \\
\hline & {$[11.4,18.1]$} & {$[12.1,17.8]$} & {$[19.2,56.0]$} & {$[13.3,21.1]$} & {$[28.0,60.9]$} \\
\hline $\mathrm{E}[\mathrm{Ai} \mid \mathrm{Xi}]$ & \multicolumn{5}{|c|}{ Option value as percent of total value of enrollment in dynamic scenario } \\
\hline \multirow[t]{2}{*}{1.0} & $7 \%$ & $8 \%$ & $12 \%$ & $11 \%$ & $41 \%$ \\
\hline & {$[4 \%, 19 \%]$} & {$[0 \%, 15 \%]$} & {$[10 \%, 42 \%]$} & {$[3 \%, 24 \%]$} & {$[-17 \%, 45 \%]$} \\
\hline \multirow[t]{2}{*}{1.5} & $25 \%$ & $25 \%$ & $34 \%$ & $30 \%$ & $26 \%$ \\
\hline & {$[22 \%, 29 \%]$} & {$[1 \%, 27 \%]$} & {$[32 \%, 53 \%]$} & {$[26 \%, 34 \%]$} & {$[20 \%, 43 \%]$} \\
\hline \multirow[t]{2}{*}{2.0} & $35 \%$ & $32 \%$ & $48 \%$ & $38 \%$ & $29 \%$ \\
\hline & {$[31 \%, 38 \%]$} & {$[5 \%, 34 \%]$} & {$[42 \%, 56 \%]$} & {$[32 \%, 42 \%]$} & {$[22 \%, 40 \%]$} \\
\hline \multirow[t]{2}{*}{2.5} & $19 \%$ & $19 \%$ & $26 \%$ & $19 \%$ & $11 \%$ \\
\hline & {$[17 \%, 23 \%]$} & {$[5 \%, 22 \%]$} & {$[22 \%, 32 \%]$} & {$[17 \%, 25 \%]$} & {$[9 \%, 16 \%]$} \\
\hline \multirow[t]{2}{*}{3.0} & $6 \%$ & $6 \%$ & $8 \%$ & $7 \%$ & $5 \%$ \\
\hline & {$[5 \%, 8 \%]$} & {$[2 \%, 7 \%]$} & {$[7 \%, 11 \%]$} & {$[6 \%, 9 \%]$} & {$[4 \%, 7 \%]$} \\
\hline \multirow[t]{2}{*}{3.5} & $3 \%$ & $2 \%$ & $4 \%$ & $3 \%$ & $11 \%$ \\
\hline & {$[1 \%, 5 \%]$} & {$[0 \%, 2 \%]$} & {$[2 \%, 6 \%]$} & {$[2 \%, 6 \%]$} & {$[8 \%, 14 \%]$} \\
\hline All & $\begin{array}{c}14 \% \\
{[12 \%, 16 \%]}\end{array}$ & $\begin{array}{c}13 \% \\
{[3 \%, 15 \%]}\end{array}$ & $\begin{array}{c}19 \% \\
{[17 \%, 27 \%]}\end{array}$ & $\begin{array}{c}15 \% \\
{[12 \%, 17 \%]}\end{array}$ & $\begin{array}{c}12 \% \\
{[10 \%, 16 \%]}\end{array}$ \\
\hline
\end{tabular}

Note: Notes: For a given parameter vector, option value is calculated as the average welfare difference between the static and dynamic scenarios when the type, shocks, and choices of each observation is simulated 100 times. Brackets present ninety percent confidence intervals, which are computed by performing this option value calculation for 200 different draws of the parameter vector from its estimated distribution. 
by the estimate of the preference shock variance $(\tau)$, but even estimates of this are not far from the base model for several alternative specifications. Only the fully unrestricted model, for which the estimated variance is substantially higher, generates option value estimates that are substantially different than the base model. Lastly, the qualitative finding that option value is greatest for moderate ability students is also robust to many of these model changes.

\section{Option value in a more general setting}

There are several ways in which the model could be generalized. Here I discuss several of these extensions and the likely impact on my estimates of option value.

The most important simplification in the current model is that it treats the labor market as an absorbing state from which students' re-enrollment decisions are not modeled. While estimating the model with only a subset of the choices is not inherently problematic, this specification ignores any option value that may arise after initial labor market entry by implicitly assuming any re-enrollment is exogenous (i.e. not a choice). This is a special case of a more general model (discussed in Web Appendix D) in which attending school and working both provide information that future decisions can be conditioned on. The omission of option value from labor market payoffs impacts my estimate of the option value in at least three ways.

First, my simulations potentially understate the overall welfare gains created by enrollment flexibility. Re-enrollment is a choice that individuals can make in response to new information learned while in the labor market, so the ability to re-enroll creates option value not quantified here. I have only quantified the option value of dropout flexibility - individuals can leave school whenever they find continuation undesirable - but re-enrollment flexibility also creates option value. The value from re-enrollment flexibility may be considerable, particularly when students cycle between enrollment and non-enrollment often (Pugatch 2011).

Second, ignoring the re-enrollment option value understates the payoffs to labor market entry, potentially biasing estimates of choice model parameters. By treating the labor market as an absorbing state, this paper approximates the true labor market entry value function with expected lifetime income. This approximation averages lifetime income across all the possible schooling outcomes for individuals who first enter the labor market at time $t$, weighted by the probability of each of these schooling outcomes occurring. ${ }^{32}$ This approximation would be exact if the probability of re-enrolling was zero or if re-enrollment was exogenous. With endogenous re-enrollment, however, this approximation will tend to understate the value of dropping out relative to continuing in school at any particular decision period. This approximation error will tend to bias the estimated size of preference shocks upwards and consequently overstate the estimated

\footnotetext{
${ }^{32}$ Payoffs are approximated by $V_{i, t}^{w}=\sum_{s=12}^{20} \operatorname{Income}_{i}(s, t) \cdot \operatorname{Pr}(s \mid$ initial entry at period $t)+\varepsilon$, where $s$ is eventual years of schooling, rather than using the true value function $V_{i, t}^{w}=u_{i, t}^{w}+\beta E\left[\max \left\{V_{i, t+1}^{w}, V_{i, t+1}^{s}\right\}\right]$.
} 
option value. ${ }^{33}$ The bottom line is that treating labor market entry as an absorbing state may bias parameter estimates and thus overstate the estimated option value.

The third issue is that by ignoring the option value that arises after labor market entry,the importance of option value to initial enrollment decisions will be overstated. In an extreme case, with completely symmetric learning (i.e. people learn as much about their tastes while working as they do attending school) and symmetric switching costs, enrollment and labor market entry would provide equal option value, so the net total informational value from enrollment itself would be zero. Though the information learned in school is valuable, this value is offset by the cost of lost information that could be gained by working. Though welfare overall is much higher from enrollment flexibility, in this case curtailing it will not affect enrollment decisions since the net return to enrolling rather than working would not change. The simulations presented in Figure 9 may thus overstate the importance of option value to enrollment decisions.

Another simplification in the current specification is that individuals are assumed to receive new draws of lifetime income only if enrolled in school, so enrollment lets people delay labor market entry until receiving a favorable draw. Relaxing this restriction so that people receive new draws while not in school will also reduce the estimated option value of enrollment flexibility. The appropriateness of this assumption can be examined using annual data on labor market outcomes, which the current dataset does not contain.

My estimates of the net option value associated with enrollment should be interpreted with these limitations in mind. Extensions that permit dynamic considerations after initial labor market entry, such as re-enrollment and repeated labor market draws, would make labor market entry more desirable and diminish the relative benefit of college enrollment. In addition, this paper has chosen to focus on the flexibility afforded to students' binary enrollment decisions, but there are many other schooling choice dimensions over which students can re-optimize after enrollment. For instance, college students can change majors, transfer schools (adjusting college quality), or adjust course sequencing in response to new information. The value of the decision flexibility in these dimensions is included in the value of the enrollment opportunity both in the dynamic and static settings, so is netted out from the option value estimate presented here. Quantifying the option value created by major, course, and school choice flexibility is an important task for future research, as these attributes are directly controlled by schools and policymakers.

\section{E. Policy consequences of educational uncertainty}

Many education policies have a temporal dimension, making option value considerations potentially important. For instance, giving students a bonus for graduating directly alters the financial gain to the final year of college but not the first three. Both community colleges and the Federal Hope tax credit explicitly alter the tuition gradient by making

\footnotetext{
${ }^{33}$ However, since this simplifcation also ignores the re-enrollment option value associated with future labor market entry points, the difference between enrollment and labor market value functions at any particular decision point is not overstated by the full amount of option value contained in the latter.
} 
the first few years of college cheaper than the last half. If students are forward-looking, the time path of incentives will enter enrollment and continuation decisions in a different way than if decisions were static. While a complete assessment of specific policies is beyond the scope of this paper, I briefly sketch how static and dynamic models of schooling may result in different policy effects. ${ }^{34}$

A static model will generally under-predict the effect of community colleges on enrollment. In addition to directly making college less expensive, community colleges increase the option value of enrollment because dropout is less costly so more people experiment with school. The static model does not fully incorporate this added informational benefit. In contrast, a static model will over-state the effects of across-the-board tuition subsidies on college completion. In the presence of large degree effects, a static model predicts a bimodal distribution of education outcomes, with many non-enrollees and many graduates, but few dropouts. Consequently, more enrollees are predicted to continue through to graduation in response to an across-the-board subsidy than would be the case in a dynamic setting. A static model which ignores endogenous dropout will also make similar predictions for front- and back-loaded tuition subsidies, but these policies can have quite different effects if choices are dynamic. A static model also over-predicts the graduation consequences of increasing academic preparedness in high school. Expected performance in college - which depends heavily on high school GPA - has much more influence on educational outcomes in the static model. If decisionmaking is dynamic, however, less weight is placed on baseline anticipated performance as new information is acquired during each year. The bottom line is that uncertainty is an important feature of educational decisions and failing to account for it may provide misleading estimates of policy effects. This is particularly true when comparing policies that have different temporal characteristics, such as community colleges (which alter the tuition gradient) or across-the-board tuition reductions (which do not).

\section{Summary and Conclusions}

This paper examines the empirical importance of uncertainty and option value to college enrollment. It is the first to quantify the magnitude of the option value that arises when individuals make decisions to invest in a college education sequentially and when the desirability of doing so is uncertain. Estimates suggest that this value is substantial. In contrast to a scenario where individuals must commit to an educational outcome ex-ante, the current flexible system increases welfare by $\$ 14,900$ on average. This represents $14 \%$ of the overall value of the opportunity to enroll in college. Moderate-ability students, who have the most uncertainty about the desirability of schooling, derive even more value from this flexibility. The traditional human capital model ignores this value.

The finding that enrollment choice flexibility substantially improves welfare has direct implications for the potential costs of student "tracking." This paper suggests that, at least in the U.S. postsecondary context, students learn quite a bit about their ability and

\footnotetext{
${ }^{34} \mathrm{~A}$ companion paper is using the estimated model to examine the option value aspects of several policy interventions specifically.
} 
preferences in the first few years of college. Forcing students to commit ex-ante makes educational outcomes more polarized by background and reduces welfare, particularly for students at the margin. This welfare loss must be weighed against any efficiency gains resulting from greater specialization through earlier tracking, such as that identified by Ofer Malamud (2010). The temporal dimension of many other education policies - for instance, whether to subsidize tuition at the beginning or end of college - have received very little attention despite their importance if schooling decisions are dynamic.

The general framework developed herein could also be used in a number of different contexts in which decisions are partially irreversible and made in the presence of uncertainty. ${ }^{35}$ One potential application is the use of "take-it-or-leave-it" job offers. Firms hiring many law or business school graduates force students to commit to a job early in the fall, possibly before their industry or locational preferences are finalized. The model implies that firms would have to compensate individuals for this loss of flexibility, through a signing bonus or higher salary. Marriage and fertility decisions are also partially irreversible and made in the presence of uncertainty. The ability to wait and acquire more information before committing to a decision thus creates option value. The effects of policies that alter the ability to reverse a decision (e.g. divorce costs) operate through this channel. Investments in health can also be understood as motivated by option value considerations. Since many health conditions (e.g. diabetes onset, lung cancer) are partially irreversible, forward-looking individuals should make costly health investments when young in order to preserve the option of being healthy when old. Subsidies for preventative care, a healthy diet, and exercise among the young can be rationalized by this option value if individuals are not completely forward-looking.

\section{Proof OF Proposition 1}

Proposition 1 (The properties of option value).

a) OptionValue $\left(\varepsilon_{i, 1}\right)$ is non-negative for all $\varepsilon_{i, 1}$.

b) OptionValue $\left(\varepsilon_{i, 1}\right)$ is greatest for individuals at the enrollment margin in the static model.

c) OptionValue $\left(\varepsilon_{i, 1}\right)$ is increasing and the critical value $\bar{\varepsilon}_{d, 1}$ is decreasing in the level of uncertainty (variance of $\varepsilon_{i, 2}$ ).

d) OptionValue $\left(\varepsilon_{i, 1}\right)$ reduces the dependence of educational outcomes on $\varepsilon_{i, 1}$.

e) The option to drop out improves welfare.

\section{PROOF:}

\footnotetext{
${ }^{35}$ Retirement decisions are one topic in labor economics to which this framework has been applied. See James H. Stock and David A. Wise (1990) and Courtney Coile and Jonathan Gruber (2007) for an application of option value to the study of retirement decisions.
} 
Consider three groups of individuals which together span the space of $\varepsilon_{i, 1}$. Group A $\left(\varepsilon_{i, 1}<\bar{\varepsilon}_{d, 1}\right)$ does not enroll under either the static or dynamic settings. Since they do not enroll, they get no value from the option to drop out. Group $C\left(\bar{\varepsilon}_{s, 1}<\varepsilon_{i, 1}\right)$ enrolls in both the dynamic and static settings. Their option value equals $E\left[\max \left\{-\rho \varepsilon_{i, 1}, \varepsilon_{i, 2}\right\}\right]$. This expression is decreasing in $\varepsilon_{i, 1}$ and positive since $E\left[\varepsilon_{i, 2} \mid \varepsilon_{i, 2}>Z\right] \geq E\left[\varepsilon_{i, 2}\right]=0$ for any value $Z$. Group $B\left(\bar{\varepsilon}_{d, 1}<\varepsilon_{i, 1}<\bar{\varepsilon}_{s, 1}\right)$ enrolls in the dynamic setting but would not if they were forced to commit to their educational decision ex-ante. For these individuals, the option value is pivotal to enrollment. This option value is equal to $\varepsilon_{i, 1}+E\left[\max \left\{0, \rho \varepsilon_{i, 1}+\varepsilon_{i, 2}\right\}\right]$. In this region, this expression is positive (by definition of $\bar{\varepsilon}_{d, 1}$ ) and monotonically increasing in $\varepsilon_{i, 1}$. Option value of individuals in this group is maximized at the boundary $\varepsilon_{i, 1}=\bar{\varepsilon}_{s, 1}=0$ where the option value equals $E\left[\max \left\{0, \varepsilon_{i, 2}\right\}\right]$. This is greater than the option value of any individuals in the other two groups. Properties $a$ and $b$ follow. For a given level of variance of $\varepsilon_{i, 2}$, the truncation point is fixed (at $-\rho \varepsilon_{i, 1}$ for Group $A$ and 0 for Group $B$ ). Since increased variance increases the truncated conditional expectation of a random variable, property $c$ follows. Like a financial option, the value of the dropout option increases in the variance of the value of the underlying asset $\left(\varepsilon_{i, 2}\right)$. Also, as OptionValue $\left(\varepsilon_{i, 1}\right)$ increases due to increased uncertainty about $\varepsilon_{i, 2}$, enrollment becomes desirable to more people, reducing the enrollment threshold. Property $d$ can be seen from the decision rules in the previous section. In the fully static case, educational outcomes are fully determined by information available in the first period. This in not true when schooling decisions are sequential. Property $e$ is a corollary of $a$ : since option value is non-negative, it improves welfare.

$*$

\section{REFERENCES}

Altonji, Joseph G. 1993. "The Demand for and Return to Education When Education Outcomes Are Uncertain." Journal of Labor Economics, 11(1): 48-83.

Arcidiacono, Peter. 2004. "Ability Sorting and the Returns to College Major." Journal of Econometrics, 121(1-2): 343-375.

Becker, Gary S., 1964. Human Capital: A Theoretical and Empirical Analysis with Special Reference to Education. New York: Columbia University Press.

Cameron, Stephen V., and James J. Heckman. 2001. "The Dynamics of Educational Attainment for Black, Hispanic, and White Males." Journal of Political Economy, 109(3): 455-499.

Card, David, 1999. "The Causal Effect of Education on Earnings." In Handbook of Labor Economics, Vol. 3A, ed. Orley Ashenfelter and David Card, 1801-1864. New York: Elsevier.

Chen, Stacey H., 2009. "Estimating the Variance of Wages in the Presence of Selection and Unobservable Heterogeneity." Review of Economics and Statistics, 90(2): 275-289.

Coile, Courtney, and Jonathan Gruber. 2007. "Future Social Security Entitlements and the Retirement Decision." Review of Economics and Statistics, 89(2): 234-246. 
Comay, Yochanan, Arie Melnik, and Moshe A. Pollatschek. 1973. "The Option Value of Education and the Optimal Path for Investment in Human Capital." International Economic Review, 14(2): 421-35.

Cunha, Flavio, James J. Heckman, and Salvador Navarro. 2005. "Separating uncertainty from heterogeneity in life cycle earnings." Oxford Economic Papers, 57(2): 191-261.

Dixit, Avinash K., and Robert S. Pindyck. 1994. Investment under Uncertainty. Princeton: Princeton University Press.

Domencich, Thomas A., and Daniel L. McFadden. 1975. Urban Travel Demand: A Behavioral Analysis. Amsterdam: North-Holland Publishing Company.

Dothan, Uri, and Joseph Williams. 1981. "Education as an Option." Journal of Business, 51(1): 117-139.

Eckstein, Zvi, and Kenneth I. Wolpin. 1999. "Why Youths Drop out of High School: The Impact of Preferences, Opportunities, and Abilities." Econometrica, 67(6): 12951339.

Eide, Eric, and Geetha Waehrer. 1998. "The Role of the Option Value of College Attendance in College Major Choice." Economics of Education Review, 17(1): 72-83.

Heckman, James J., Lance J. Lochner, and Petra E. Todd. 2006. "Earnings Functions, Rates of Return and Treatment Effects: The Mincer Equation and Beyond." In Handbook of the Economics of Education, Vol. 1, ed. Erik Hanushek and Finis Welch, 307458. Amsterdam: Elsevier.

Heckman, James J., and Salvador Navarro. 2007. "Dynamic Discrete Choice and Dynamic Treatment Effects." Journal of Econometrics, 136(2): 341-396.

Heckman, James J., and Burton Singer. 1984. "A Method for Minimizing the Impact of Distributional Assumptions in Econometric Models for Duration Data." Econometrica, 52 (2): 271-320.

Heckman, James J., and Sergio Urzua. 2008. "The Option Value of Educational Choices and the Rate of Return to Educational Choices." Unpublished.

Hungerford, Thomas, and Gary Solon. 1987. "Sheepskin Effects in the Returns to Education." Review of Economics and Statistics, 69(1): 175-177.

Jaeger, David A., and Marianne E. Page. 1996. "Degrees Matter: New Evidence on Sheepskin Effects in Returns to Education." Review of Economics and Statistics, 78(4): 733-740.

Kane, Thomas J., and Cecilia E. Rouse. 1995. "Labor Market Returns to Two- and Four-Year College." The American Economic Review, 85(3): 600-614.

Keane, Michael P., and Kenneth I. Wolpin. 1997. "The Career Decisions of Young Men.” Journal of Political Economy, 105(3): 473-522.

Kilburn, M. Rebecca, Lawrence M. Hanser, and Jacob A. Klerman. 1998. Estimating AFQT Scores for NELS Respondents. Santa Monica: RAND, MR-818-OSD/A, 1998.

Malamud, Ofer, 2010. "Breadth vs. Depth: The Timing of Specialization in Higher Education." LABOUR: Review of Labour Economics and Industrial Relations, 24(4): 359-390. 
Manski, Charles F., 1989. "Schooling as Experimentation: A Re-Appraisal of the Postsecondary Dropout Phenomenon." Economics of Education Review, 8(4): 305-312.

Manski, Charles F., 1991. "Nonparametric Estimation of Expectations in the Analysis of Discrete Choice Under Uncertainty." In Nonparametric and Semiparametric Methods in Econometrics and Statistics. ed. William A. Barnett, James Powell, and George E. Tauchen, 259-275. New York: Cambridge University Press.

Oreopoulos, Philip, Till von Wachter and Andrew Heisz. 2006. "The Short- and LongTerm Career Effects of Graduating in a Recession: Hysteresis and Heterogeneity in the Market for College Graduates." National Bureau of Economic Research Working Paper 12159.

Park, Jin Heum. 1999. "Estimation of Sheepskin Effects Using the Old and the New Measures of Educational Attainment in the Current Population Survey." Economics Letters, 62(2): 237-240.

Pindyck, Robert S. 1993. "Investments of Uncertain Cost." Journal of Financial Economics, 34(1): 53-76.

Pugatch, Todd. 2011. "Bumpy Rides: School to Work Transitions in South Africa." https://sites.google.com/site/toddpugatch/home/research.

Rust, John. 1987. "Optimal Replacement of GMC Bus Engine: An Empirical Model of Harold Zurcher." Econometrica, 55(5): 999-1033.

Stinebrickner, Todd R., and Raph Stinebrickner. 2009. "Learning about Academic Ability and the College Drop-out Decision." National Bureau of Economic Research Working Paper 14810.

Stock, James H., and David A. Wise. 1990. "Pensions, the Option Value of Work, and Retirement." Econometrica, 58(5): 1151-1180.

Taber, Christopher R. 2000. "Semiparametric Identification and Heterogeneity in Dynamic Programming Discrete Choice Models." Journal of Econometrics, 96(2): 201229.

Weisbrod, Burton A. 1962. "Education and Investment in Human Capital." The Journal of Political Economy, 70(5): 106-123. 